University of Nebraska - Lincoln

DigitalCommons@University of Nebraska - Lincoln

\title{
Roaming radicals in the thermal decomposition of dimethyl ether: Experiment and theory
}

R. Sivaramakrishnan

Argonne National Laboratory, Argonne, IL

J. Michael

Argonne National Laboratory, Argonne, IL

A. Wagner

Argonne National Laboratory, Argonne, IL

R. Dawes

Missouri University of Science and Technology, Rolla, MO

A. Jasper

Sandia National Laboratories, Livermore, CA

See next page for additional authors

Follow this and additional works at: https://digitalcommons.unl.edu/usdoepub

Part of the Bioresource and Agricultural Engineering Commons

Sivaramakrishnan, R.; Michael, J.; Wagner, A.; Dawes, R.; Jasper, A.; Harding, L.; Georgievskii, Y.; and Klippenstein, S., "Roaming radicals in the thermal decomposition of dimethyl ether: Experiment and theory" (2011). US Department of Energy Publications. 131.

https://digitalcommons.unl.edu/usdoepub/131

This Article is brought to you for free and open access by the U.S. Department of Energy at DigitalCommons@University of Nebraska - Lincoln. It has been accepted for inclusion in US Department of Energy Publications by an authorized administrator of DigitalCommons@University of Nebraska - Lincoln. 


\section{Authors}

R. Sivaramakrishnan, J. Michael, A. Wagner, R. Dawes, A. Jasper, L. Harding, Y. Georgievskii, and S. Klippenstein 


\title{
Roaming radicals in the thermal decomposition of dimethyl ether: Experiment and theory
}

\author{
R. Sivaramakrishnan ${ }^{\text {a }}$, J.V. Michael ${ }^{\mathrm{a}, *}$, A.F. Wagner ${ }^{\mathrm{a}, *}$, R. Dawes ${ }^{\text {b,c }}$, A.W. Jasper ${ }^{\mathrm{c}}$, L.B. Harding ${ }^{\mathrm{a}}$, \\ Y. Georgievskii ${ }^{a}$, S.J. Klippenstein ${ }^{\mathrm{a}}$ \\ ${ }^{a}$ Chemical Sciences and Engineering Division, Argonne National Laboratory, Argonne, IL 60439, USA \\ ${ }^{\mathrm{b}}$ Missouri University of Science and Technology, Rolla, MO 65409, USA \\ ${ }^{\text {c } C o m b u s t i o n ~ R e s e a r c h ~ F a c i l i t y, ~ S a n d i a ~ N a t i o n a l ~ L a b o r a t o r i e s, ~ L i v e r m o r e, ~ C A ~ 94551, ~ U S A ~}$
}

\section{A R T I C L E I N F O}

\section{Article history:}

Received 19 November 2010

Received in revised form 14 December 2010

Accepted 15 December 2010

Available online 13 January 2011

\section{Keywords:}

$\mathrm{H}+$ dimethyl ether

Transition state theory

$\mathrm{Ab}$ initio

Shock tube

Abstraction

\begin{abstract}
A B S T R A C T
The thermal dissociation of dimethyl ether has been studied with a combination of reflected shock tube experiments and ab initio dynamics simulations coupled with transition state theory based master equation calculations. The experiments use the extraordinary sensitivity provided by H-atom ARAS detection with an unreversed light source to measure both the total decomposition rate and the branching to radical products versus molecular products, with the molecular products arising predominantly through roaming according to the theoretical analysis. The experimental observations also provide a measure of the rate coefficient for $\mathrm{H}+\mathrm{CH}_{3} \mathrm{OCH}_{3}$. An evaluation of the available experimental results for $\mathrm{H}+\mathrm{CH}_{3} \mathrm{OCH}_{3}$ can be expressed by a three parameter Arrhenius expression as,
\end{abstract}

$k=6.54 \times 10^{-24} T^{4.13} \exp (-896 / T) \mathrm{cm}^{3}$ molecule $^{-1} \mathrm{~s}^{-1}(273-1465 \mathrm{~K})$

The potential energy surface is explored with high level ab initio electronic structure theory. The dynamics of roaming versus radical formation is studied with a reduced dimensional trajectory approach. The requisite potential energy surface is obtained from an interpolative moving least squares fit to wide-ranging ab initio data for the long-range interactions between methyl and methoxy. The predicted roaming and radical micro-canonical fluxes are incorporated in a master equation treatment of the temperature and pressure dependence of the dissociation process. The tight (i.e., non-roaming) transition states leading to a variety of additional molecular fragments are also included in the master equation analysis, but are predicted to have a negligible contribution to product formation. The final theoretical results reliably reproduce the measured dissociation rate to radical products reported here and are well reproduced over the $500-2000 \mathrm{~K}$ temperature range and the $0.01-300$ bar pressure range by the following modified Arrhenius parameters for the Troe falloff format:

$$
\begin{aligned}
& k_{1, \infty}(T)=2.33 \times 10^{19} T^{-0.661} \exp (-42345 / T) \mathrm{s}^{-1} \\
& k_{1,0}(T)=2.86 \times 10^{35} T^{-11.4} \exp (-46953 / T) \mathrm{cm}^{3} \text { molecule }^{-1} \mathrm{~s}^{-1} \\
& F_{\text {cent }}(T)=\exp (-T / 880)
\end{aligned}
$$

The experimentally observed branching ratio of $0.19 \pm 0.07$ provides a direct measure of the contribution from the roaming radical mechanism. The theoretical analysis predicts a much smaller roaming contribution of 0.02 .

(C) 2010 The Combustion Institute. Published by Elsevier Inc. All rights reserved.
* Corresponding authors. Address: D-193, Bldg. 200, Chemical Sciences and Engineering Division, Argonne National Laboratory, Argonne, IL 60439, USA. Fax: +1 6302529570 (J.V. Michael), fax: +1 6302529292 (A.F. Wagner).

E-mail addresses: jmichael@anl.gov (J.V. Michael), wagner@anl.gov (A.F. Wagner).

\section{Introduction}

The simplest of the ethers, dimethyl ether (DME), is a synthetic fuel produced commonly from syngas $\left(\mathrm{CO}, \mathrm{H}_{2}\right)$ and also from a variety of other feedstocks such as coal, natural gas, biomass, and blends of these. When DME burns it is smokeless, and it is therefore a favorable replacement candidate for diesel fuel from an emissions perspective. In addition to being a potential diesel fuel 
replacement, DME can also be used as (1) a fuel in gas turbines for power generation, (2) an LPG substitute, (3) a hydrogen source for fuel cells, and (4) as a feedstock for chemicals [1]. Recent interest in DME as an alternative fuel and as a potential additive has spurred a number of combustion studies that have been highlighted in a special issue [2].

Thermal decomposition plays a significant role in the combustion kinetics of DME [3]. In all previous experimental studies [4-10] the thermal decomposition of $\mathrm{CH}_{3} \mathrm{OCH}_{3}$ is presumed to undergo $\mathrm{C}-\mathrm{O}$ bond fission through $\mathrm{R} 1$,

$\mathrm{CH}_{3} \mathrm{OCH}_{3} \rightarrow \mathrm{CH}_{3}+\mathrm{CH}_{3} \mathrm{O}$

However, recent theoretical studies [11] suggest the ubiquity of roaming radical processes in a variety of molecular systems. For DME, the roaming radical mechanism, if present, will lead to the formation of molecular products, $\mathrm{CH}_{4}$ and $\mathrm{CH}_{2} \mathrm{O}$, through $\mathrm{R} 2$,

$\mathrm{CH}_{3} \mathrm{OCH}_{3} \rightarrow \mathrm{CH}_{3} \cdots \mathrm{OCH}_{3} \rightarrow \mathrm{OCH}_{3} \cdots \mathrm{CH}_{3} \rightarrow \mathrm{CH}_{4}+\mathrm{CH}_{2} \mathrm{O}$

The branching between radical (R1) and molecular (R2) products might be expected to have a significant impact on the combustion properties for DME.

Early studies on roaming radical mechanisms considered the photodissociation of small molecular systems. For example, in formaldehyde it was shown that during the process of $\mathrm{C}-\mathrm{H}$ bond fission some of the departing $\mathrm{H}$-atoms can roam around the $\mathrm{HCO}$ moiety at long-range and then abstract a hydrogen atom with no further activation energy to produce $\mathrm{H}_{2}+\mathrm{CO}[12]$. Subsequent experimental and theoretical studies on acetaldehyde photodissociation demonstrated the presence of an analogous process with a roaming $\mathrm{CH}_{3}$ radical to give $\mathrm{CH}_{4}+\mathrm{CO}$ [13-15].

The branching to a roaming channel in a thermal dissociation was first identified in a combination of experimental and theoretical studies $[16,17]$ on acetaldehyde. DME represents another potential candidate for an important roaming radical channel in a thermal dissociation. A preliminary scan of the DME potential energy surface reveals that the saddle point for the roaming process $\left(\mathrm{CH}_{3} \ldots \mathrm{OCH}_{3} \rightarrow \mathrm{OCH}_{3} \ldots \mathrm{CH}_{3}\right)$ is $\sim 2 \mathrm{kcal} / \mathrm{mol}$ below the $\mathrm{C}-\mathrm{O}$ bond fission asymptote. For $\mathrm{CH}_{3} \mathrm{CHO}$, the roaming radical transition state was $\sim 1 \mathrm{kcal} / \mathrm{mol}$ below the $\mathrm{C}-\mathrm{C}$ bond fission asymptote [17]. Consequently, one might expect in DME a similar if not larger contribution from the roaming radical mechanism than in $\mathrm{CH}_{3} \mathrm{CHO}$.

In this work, we employ a combination of experimental measurements and theoretical analyses in a detailed study of the roaming fraction for the thermal decomposition of DME. This analysis is closely related to the prior study of the thermal dissociation of acetaldehyde $[16,17]$. The experimental component of this work employs the reflected shock-tube technique with a high sensitivity $\mathrm{H}$-atom Atomic Resonance Absorption Spectroscopy (ARAS) detection scheme to minimize secondary reactions and determine absolute yields of products. At high temperatures, $\mathrm{CH}_{3} \mathrm{O}$ instantaneously dissociates to $\mathrm{H}+\mathrm{CH}_{2} \mathrm{O}$, and, therefore, temporal $\mathrm{H}$-atom measurements are good indicators for the rate of $\mathrm{R} 1$.

One aspect of the theoretical analysis involves ab initio transition state theory based master equation calculations of the rate coefficients for the various decomposition processes. This analysis indicates that the channels leading to $\mathrm{H}_{2}+\mathrm{CH}_{3} \mathrm{OCH}, \mathrm{H}+\mathrm{CH}_{3} \mathrm{OCH}_{2}$, and ${ }^{1} \mathrm{CH}_{2}+\mathrm{CH}_{3} \mathrm{OH}$ are kinetically insignificant. As discussed below, the present experimental measurements then directly provide the branching between the $\mathrm{C}-\mathrm{O}$ bond dissociation channel (R1) and the roaming channel (R2).

The primary focus of the theoretical analysis is on the direct calculation of the roaming fraction as a complement to the experimental measurements of this quantity. These calculations are carried out with a reduced dimensional trajectory (RDT) approach as described in Ref. [17]. The RDT calculations require a six-dimensional potential energy surface describing the interaction between rigid $\mathrm{CH}_{3}$ and $\mathrm{CH}_{3} \mathrm{O}$ radicals for arbitrary orientations and separation. Here, this potential energy surface is generated from a novel application of the interpolative moving least squares (IMLS) fitting approach [18], with the underlying ab initio data obtained from multi-reference second order perturbation theory (CASPT2).

The experimental work adds significantly to the database for DME decomposition. The majority of the prior DME thermal decomposition studies were carried out in flow reactors [4-8]. These studies used large initial concentrations of fuel, and, therefore, the thermal decomposition rate coefficients relied heavily on detailed chemical kinetics modeling. In order to better characterize the high-temperature thermal decomposition rates, two recent studies have been carried out using shock tubes. The Fernandes et al. [9] study used H-atom ARAS as the diagnostic for measuring rate coefficients for R1. By contrast, the Cook et al. [10] study used mixtures of DME in excess $\mathrm{O}_{2}$ with $\mathrm{OH}$-absorption as the diagnostic. The resulting $\mathrm{H}$-atoms from $\mathrm{CH}_{3} \mathrm{O}$ decomposition react with excess $\mathrm{O}_{2}$ to form $\mathrm{OH}$ through the chain branching reaction, $\mathrm{H}+\mathrm{O}_{2} \rightarrow \mathrm{OH}+\mathrm{O}$, and therefore, the $\mathrm{OH}$-temporal profiles can then be used to obtain rate constants for R1.

Both new studies employed analytical techniques that allowed the use of much lower initial concentrations of DME than earlier studies [4-8]; however, they still need to use a chemical kinetic model to extract rate coefficients for R1. Even the H-atom ARAS study of Fernandes et al. [9], with the lowest initial DME concentrations of any published DME kinetics experiment, still used relatively large initial concentrations. As a result, one secondary reaction, namely $\mathrm{H}+\mathrm{CH}_{3} \mathrm{OCH}_{3} \rightarrow$ products, had a major effect on the long time values of $[\mathrm{H}]$. These authors were able to specify rate constants for this reaction through modeling, and subsequently, also for the thermal decomposition.

Not only are all prior DME kinetics studies complicated by secondary reaction perturbations, but, more importantly for this study, absolute yields for various thermal decomposition channels could not be directly measured. In contrast, the present work uses a higher sensitivity $\mathrm{H}$-atom ARAS detection scheme to minimize secondary reactions, and this allows determinations for absolute yields of products. The resonance light source used in this laboratory is unreversed, giving an increase of $\sim 5-10$ in sensitivity over that used by Fernandes et al. [9], who also used the ARAS technique but with a substantially reversed resonance light source [19]. As in earlier work [20], we show that this unreversed source allows experiments to be performed under pseudo-first order conditions; i.e., with no secondary reaction interferences.

We also extend these ultra-dilute pseudo-first order studies to experiments with roughly the same $\left[\mathrm{CH}_{3} \mathrm{OCH}_{3}\right]_{0}$ as Fernandes et al. [9]. These higher concentration experiments expand our rate constant database for DME decomposition to lower- $T$, and allow for the determination of rate constants for $\mathrm{H}+\mathrm{CH}_{3} \mathrm{OCH}_{3}$ via the modeling of the temporal $\mathrm{H}$-atom profiles. The measurements for the $\mathrm{H}+\mathrm{DME}$ reaction extend the experimental rate database for that reaction to higher- $T$ than the recent measurements of Takahashi et al. [21].

\section{Experiment}

The present experiments were performed with the reflected shock-tube technique using $\mathrm{H}$-atom ARAS detection. The methods and the apparatus currently being used have been previously described $[22,23]$ and only a brief description of the experiment will be presented here.

The shock-tube was constructed entirely from a $7-\mathrm{m}(10.2 \mathrm{~cm}$ o.d.) 304 stainless steel tube with the cylindrical section being separated from the He driver chamber by a 4 mil unscored 
1100-H18 aluminum diaphragm. The tube was routinely pumped between experiments to less than $1.3 \times 10^{-11}$ bar by an Edwards Vacuum Products Model CR100P packaged pumping system. Shock-wave velocities were measured with eight equally spaced pressure transducers (PCB Piezotronics, Inc., Model 113A21) mounted along the downstream part of the test section and recorded with a 4094C Nicolet digital oscilloscope. Temperature and density in the reflected shock-wave regime were calculated from this velocity. This procedure has been given previously, and corrections for boundary layer perturbations have been applied [24-26]. The oscilloscope was triggered by pulses derived from the last velocity gauge signal. The photometer system was radially located at $6 \mathrm{~cm}$ from the endplate.

For $\mathrm{H}$-atom detection, the lenses were crystalline $\mathrm{MgF}_{2}$, and the resonance lamp beam intensity (filtered through $6 \mathrm{~cm}$ of dry air $\left(21 \% \mathrm{O}_{2}\right)$ to isolate the Lyman- $\alpha_{\mathrm{H}}$ wavelength at $\left.121.6 \mathrm{~nm}\right)$, was measured by an EMR G14 solar blind photomultiplier tube, as described previously [19,27-29], and was recorded with a LeCroy model LC334A oscilloscope. In order to measure the fraction of non-Lyman- $\alpha_{H}$ present in the resonance absorption emission lamp, an $\mathrm{H}_{2}$ discharge flow system was used to create large [ $\left.\mathrm{H}\right]$ between the lamp and shock tube lens [30], thereby removing all of the Lyman- $\alpha_{H}$ lamp emission. The $H$-atom experiments were then performed with the discharge system turned off.

\subsection{Gases}

High purity He (99.995\%), used as the driver gas, was from AGA Gases. Research grade $\mathrm{Kr}$ (99.999\%), the diluent gas in reactant mixtures, was from Praxair, Inc. The $\sim 10 \mathrm{ppm}$ impurities $\left(\mathrm{N}_{2}<5 \mathrm{ppm}, \mathrm{O}_{2}<2 \mathrm{ppm}, \mathrm{Ar}<1 \mathrm{ppm}, \mathrm{CO}_{2}<0.5 \mathrm{ppm}, \mathrm{H}_{2}<1 \mathrm{ppm}\right.$, $\mathrm{H}_{2} \mathrm{O}<3 \mathrm{ppm}, \mathrm{Xe}<2 \mathrm{ppm}$, and $\mathrm{THC}<0.2 \mathrm{ppm}$ ) are all either inert or in sufficiently low concentration so as to not perturb H-atom profiles. For H-atom detection, the microwave driven resonance lamp operated at $35 \mathrm{~W}$ and 1.4 Torr of ultra-high purity He (99.999\%) (effective Doppler temperature, $470 \mathrm{~K}$ [30]). This grade of He contains a trace of hydrogenous impurities that is sufficient to give measurable Lyman- $\alpha_{\mathrm{H}}$ radiation. $\mathrm{CH}_{3} \mathrm{OCH}_{3}$ (research grade, 99.9\%) was obtained from Fluka and was further purified by bulbto-bulb distillation, retaining only the middle third for mixture preparation. Gas mixtures were accurately prepared from pressure measurements using a Baratron capacitance manometer in an all glass high-purity vacuum line.

\section{Theory}

\subsection{Electronic structure calculations}

The $\mathrm{CH}_{3}+\mathrm{CH}_{3} \mathrm{O}$ interaction potential was characterized using the multireference CASPT2 method [31,32], a minimal active space of four electrons in three orbitals, and the aug-cc-pVDZ basis set. Two states were included in the CASSCF step of the CASPT2 calculation. At large fragment separations, the $(4 \mathrm{e}, 3 \mathrm{o})$ active space corresponds to the radical orbital on the methyl fragment and the two $p$ orbitals on the $\mathrm{O}$ atom of the methoxy fragment. Limited calculations were performed with the aug-cc-pVTZ basis set to examine the basis set convergence for key aspects of the interaction potential. The Molpro electronic structure package [33] was used.

The methoxy fragment was constrained to have $C_{3 v}$ symmetry, and both fragments were fixed at their isolated B3LYP/6-311++ $\mathrm{G}^{* *}$ geometries when calculating the interaction potential. The symmetrized $C_{3 v}$ structure was chosen for the methoxy radical instead of the Jahn-Teller distorted $C_{s}$ structure to simplify the potential energy surface fitting and the dynamics calculations.
In addition to the CASPT2 calculations described above on the $\mathrm{CH}_{3}+\mathrm{CH}_{3} \mathrm{O}$ interaction potential, we also report calculations on possible competing decomposition processes. In these calculations stationary point geometries were optimized at the $\operatorname{CCSD}(\mathrm{T}) /$ aug-cc-pVDZ level followed by single point $\operatorname{CCSD}(\mathrm{T})$ calculations with aug-cc-pVTZ and aug-cc-pVQZ basis sets. The energies from the two single point calculations were then extrapolated to the complete basis set (CBS) limit.

\subsection{Analytic six-dimensional surface}

An analytic representation of the $\mathrm{CH}_{3}+\mathrm{CH}_{3} \mathrm{O}$ CASPT2(4e,3o)/ aug-cc-pVDZ rigid fragment interaction potential energy surface (PES) was developed using a generalization of the recently described [34] rigid fragment interpolative moving least squares (IMLS) method [18]. The IMLS method was used here because it provides an automated strategy for converging the fitted surface to a specified accuracy with a minimal number of ab initio calculations. Briefly, an initial set of 2000 "seed" geometries was generated with coordinates distributed quasirandomly using a six dimensional Sobol sequence [35] evenly over the five orientation angles and with center of mass separations $r_{0}$ from 5 to $20 \mathrm{a}_{0}$ $\left(1 \mathrm{a}_{0}=0.529 \AA\right)$. The distribution of center of mass separations was biased to favor small values of $r_{0}$ with the probability $p\left(r_{0}\right)=0.953 \exp \left(-0.37\left(r_{0} / \mathrm{au}-5\right)\right)+0.047$. Ab initio calculations of the energy and gradient using the CASPT2 method described above were carried out at the seed geometries. The resulting energies and gradients were used to obtain two initial IMLS fits: one "high order" fit and one "low order" fit. As discussed below, the order of the IMLS fit determines its flexibility. The high order fit is flexible enough to accurately describe the interaction potential. The low order fit is less flexible and is used to estimate the interpolation error of the high order fit. Specifically, the RMS and mean deviations in the two fits (evaluated at 40,000 randomly selected geometries) were evaluated; these deviations have been shown to be good indicators of the overall accuracy of the high order fit. The test points were again biased toward short values of $r_{0}$. The biased test set has larger estimated errors than unbiased test sets, but it yields a more useful probe of the chemically relevant regions.

The high order IMLS fit was systematically improved by generating additional ab initio energies and gradients at geometries identified as having the largest high order-low order differences. We note that by construction both high order and low order IMLS fits have essentially zero fitting error at the ab initio points included in the fits. The incorporation of new ab initio data into the fit produces new fits with essentially zero error at the new geometries as well. The new ab initio data were constrained to be no more than $15 \mathrm{kcal} / \mathrm{mol}$ above the separated fragments asymptote. Ab initio energies and gradients were calculated in parallel at these geometries ( 20 at a time) and added to the data set. New high and low order fits were generated using the augmented ab initio data set. This iterative process was repeated, systematically improving the quality of the fit until the RMS interpolation error was reduced below $0.3 \mathrm{kcal} / \mathrm{mol}$. The final high order fit consists of $4366 \mathrm{ab}$ initio energies and gradients and has RMS and mean interpolation errors of 0.28 and $0.13 \mathrm{kcal} / \mathrm{mol}$, respectively. Note: the low order fit was used to estimate the interpolation errors and to identify the geometries at which new ab initio data were added to the set. The high order IMLS fit was used exclusively in the RDT dynamics calculations.

The symmetry of the $\mathrm{CH}_{3}$ and $\mathrm{CH}_{3} \mathrm{O}$ fragments was exploited in the IMLS fit as follows. The reference orientation for each fragment was chosen such that the threefold symmetry axes were aligned with the $z$-axis of the lab frame, thus permitting threefold mappings of the related Euler angles $\gamma_{1}$ and $\gamma_{2}$. In addition, after each ab initio calculation, a second symmetry-related data point was 
obtained (at no cost) at the equivalent geometry obtained by flipping the methyl fragment so that the methoxy fragment is found on the opposite side of the plane of the methyl. Use of symmetry in this way improves overall fitting efficiency by a factor of 18 .

The above has not described two critical features of any IMLS application: the basis set and the distance metric. The IMLS energy at any geometry $\vec{r}$ is evaluated as a weighted sum of local expansions $V_{j}$,

$V(\vec{r})=\sum_{j} w_{j}(\vec{r}) V_{j}(\vec{r})$

centered at the geometries of the ab initio data. The basis function $B_{k}$ defines the local expansion

$V_{j}(\vec{r})=c_{j, 0}+\sum_{k} c_{j, k} B_{k}(\vec{r})$

where $c_{j, k}$ are determined from weighted least squares fits to the full set of $\mathrm{ab}$ initio energies and gradients. The $w_{j}$ can take many forms but must be steeply peaked so as to reproduce the ab initio energies and gradients. The form we use [18] is:

$w_{j}(\vec{r})=\exp \left[-\left(d\left(\vec{r}_{j}, \vec{r}\right) / D_{j}\right)^{2}\right] /\left(\left(d\left(\vec{r}_{j}, \vec{r}\right) / D_{j}\right)^{6}+\varepsilon\right)$

where $d$ is the distance metric, $D_{j}$ is related to the density of ab initio points near $\vec{r}_{j},[18]$ and $\varepsilon$ is a small number $\left(10^{-14}\right.$ in this case $)$ to prevent singularities as $d$ approaches 0 .

The functional forms of the basis set and the coordinates in which they are expressed can significantly influence the accuracy of the fit relative to the number of ab initio data points in the fit. Here, the angular basis functions $\Omega$ were chosen to be products of rigid rotation functions,

$$
\begin{aligned}
& \Omega_{L_{1}, L_{2}, K_{1}, K_{2}, M}\left(\gamma_{1}, \beta_{1}, \gamma_{2}, \beta_{2}, \alpha_{1}-\alpha_{2}\right) \\
& \quad=R_{M, K_{1}}^{L_{1}}\left(0, \beta_{1}, \gamma_{1}\right) R_{-M, K_{2}}^{L_{2}}\left(\alpha_{1}-\alpha_{2}, \beta_{2}, \gamma_{2}\right)
\end{aligned}
$$

where $\alpha_{i}, \beta_{i}$, and $\gamma_{i}$ are Euler angles for fragments $i, R_{M, K}^{L}$ are the real rotation matrices based on Wigner $d$-functions, [36] and the indices $L_{1}, L_{2}, K_{1}, K_{2}$, and $M$ define the nodal structure of the basis function. The sum of $L_{1}$ and $L_{2}$ was limited to a maximum value of $L_{\max }, K_{1}$ and $K_{2}$ may vary from $-L_{1}$ to $L_{1}$ and $-L_{2}$ to $L_{2}$, respectively, and $M$ may vary from 0 to $\min \left(L_{1}, L_{2}\right)$. This choice for $\Omega$ is most appropriate at long-range, where the interaction potential is characterized by weak interactions. Although these angular basis functions are less suitable for short range geometries, the local expansions in the IMLS strategy allow for an accurate representation of the ab initio data over the entire range of geometries considered here.

The radial dependence of the basis functions was expressed as powers of the exponential of $r_{0}$ with a range parameter $a=1 \AA^{-1}$, such that

$B_{k}\left(r_{0}, \gamma_{1}, \beta_{1}, \gamma_{2}, \beta_{2}, \alpha_{1}-\alpha_{2}\right)=\exp \left(-a r_{0}\right)^{N} \Omega_{L_{1}, L_{2}, K_{1}, K_{2}, M}$

where $k=\left(N, L_{1}, L_{2}, K_{1}, K_{2}, M\right)$ is a composite basis function index. $L_{\max }$ and the maximum allowed value of $N$ determine the order of the basis. For the higher order basis set, we choose $L_{\max }=3$ and $N=1-4$, which results in 437 basis functions for each local expansion. For the lower order basis set, we choose $L_{\max }=2$ and $N=1-3$, which results in 106 basis functions for each local expansion.

The geometry dependent weights $w_{j}$ in Eq. (E1) are a function of the distance metric $d$ that defines the effective "distance" between an evaluation geometry $\vec{r}$ and the geometries $\vec{r}_{j}$ of each of the ab initio data. In the present application,

$d\left(\vec{r}_{j}, \vec{r}\right)^{2} \equiv \min _{\Omega} \sum_{i}\left|X_{i}\left(\vec{r}_{j}\right)-X_{i}(\vec{r})\right|^{2}$

where $X_{i}$ is the Cartesian vector of atom $i$ and $\min _{\Omega}$ denotes minimization with respect to the relative rotation of the two geometries about the axis connecting the centers of mass of the two fragments. This minimization is given by an analytic expression but in practice requires that all the ab initio points and each evaluation point be externally rotated so that the separation vector between the centers of mass of the two fragments are coincident with a common axis (say the $z$ axis) whose origin is the center of mass of the total system. Permutation symmetry influences the value of $d$ defined by Eq. (E6) because it changes the identity of the $i$ th atom at the evaluation point relative to that at the ab initio point. As discussed above, there is an 18 -fold permutation symmetry (relevant to rigid rotations) resulting in 18 different possible values of $d$, the minimum of which defines the final value of $d$ used in $w_{j}$.

The use of gradient data, the specialized fitting basis, and the optimized and automated selection of ab initio information produced a great improvement in efficiency relative to the previous study of acetaldehyde [17]. The present IMLS fit required only $4366 \mathrm{ab}$ initio energies and gradients, whereas in the acetaldehyde study a fit of permutationally invariant direct product multinomials in Morse variables required $\sim 100,000$ energies and considerable human effort in order to produce a fit of comparable quality.

\subsection{One-dimensional corrections}

One-dimensional corrections were developed to account for geometry relaxation, changes in the zero-point energy of the reactants, and limitations in the aug-cc-pVDZ basis set. Three approaches of the $\mathrm{CH}_{3}$ and $\mathrm{CH}_{3} \mathrm{O}$ fragments were considered: the minimum energy path for association (as), the minimum energy path for abstraction (ab), and a cut through the neighborhood of the roaming saddle point (sp). Along each approach, the CBS limit was estimated using the aug-cc-pVDZ and aug-cc-pVTZ basis sets and assuming $l^{-3}$ scaling, where $l=2$ and 3 for the aug-cc-pVDZ and aug-cc-pVTZ basis sets, respectively. The energetic effect and the change in the zero-point energy due to geometry relaxation were also calculated. To allow for fragment relaxation, these calculations were carried out for the $A^{\prime}$ state equilibrium geometry of Jahn-Teller distorted $\mathrm{CH}_{3} \mathrm{O}$. The CBS correction was found to be very similar for the $\mathrm{C}_{\mathrm{s}}$ and $\mathrm{C}_{3 \mathrm{v}} \mathrm{CH}_{3} \mathrm{O}$. For the abstraction correction, the geometry relaxation correction could not be reliably calculated for $\mathrm{C}-\mathrm{H}$ distances shorter than $4 \mathrm{au}$, and the corrections along the abstraction approach were approximated at these distances.

The magnitudes of the individual and overall corrections are shown in Fig. 1. For the association channel in Fig. 1a, the magnitudes of the corrections are similar to those reported previously for $\mathrm{CH}_{3}+\mathrm{HCO}$ [17]. The well depth for the constrained-fragment abstraction is only $2.8 \mathrm{kcal} / \mathrm{mol}$ for $\mathrm{CH}_{3}+\mathrm{CH}_{3} \mathrm{O}$, as shown in Fig. $1 \mathrm{~b}$, and the geometry relaxation correction for this channel is greater than $10 \mathrm{kcal} / \mathrm{mol}$ at short distances. The geometry correction therefore qualitatively changes the shape of the potential energy surface for the $\mathrm{CH}_{3}+\mathrm{CH}_{3} \mathrm{O}$ abstraction. For the $\mathrm{CH}_{3}+\mathrm{HCO}$ abstraction, on the other hand, the geometry correction was not greater than the depth of the constrained fragment well at relevant inter-fragment distances [17]. For the saddle point correction shown in Fig. 1c, the uncorrected energies and the individual corrections are of much smaller scale than those of the other two channels. The total correction is smaller than the other two channels and has a much weaker dependence on the fragment separation.

The one-dimensional corrections for the three approaches were combined into a global correction $V_{\text {cor }}$ based on spline fits to the total corrections for each of the three approaches: $V_{\text {as }}$, which is a function of the $\mathrm{C}^{\prime}-\mathrm{O}$ distance $\left(\mathrm{C}^{\prime}\right.$ labels the methyl carbon), $V_{\mathrm{sp}}$, which is a function of the $C^{\prime}-Q$ distance $(Q$ is the midpoint of C-O), and $\bar{V}_{\mathrm{ab}}$, which is a weighted average of a spline fit $V_{\mathrm{ab}}$ to the total abstraction correction potential evaluated at each of the three $\mathrm{C}^{\prime}-\mathrm{H}$ distances 

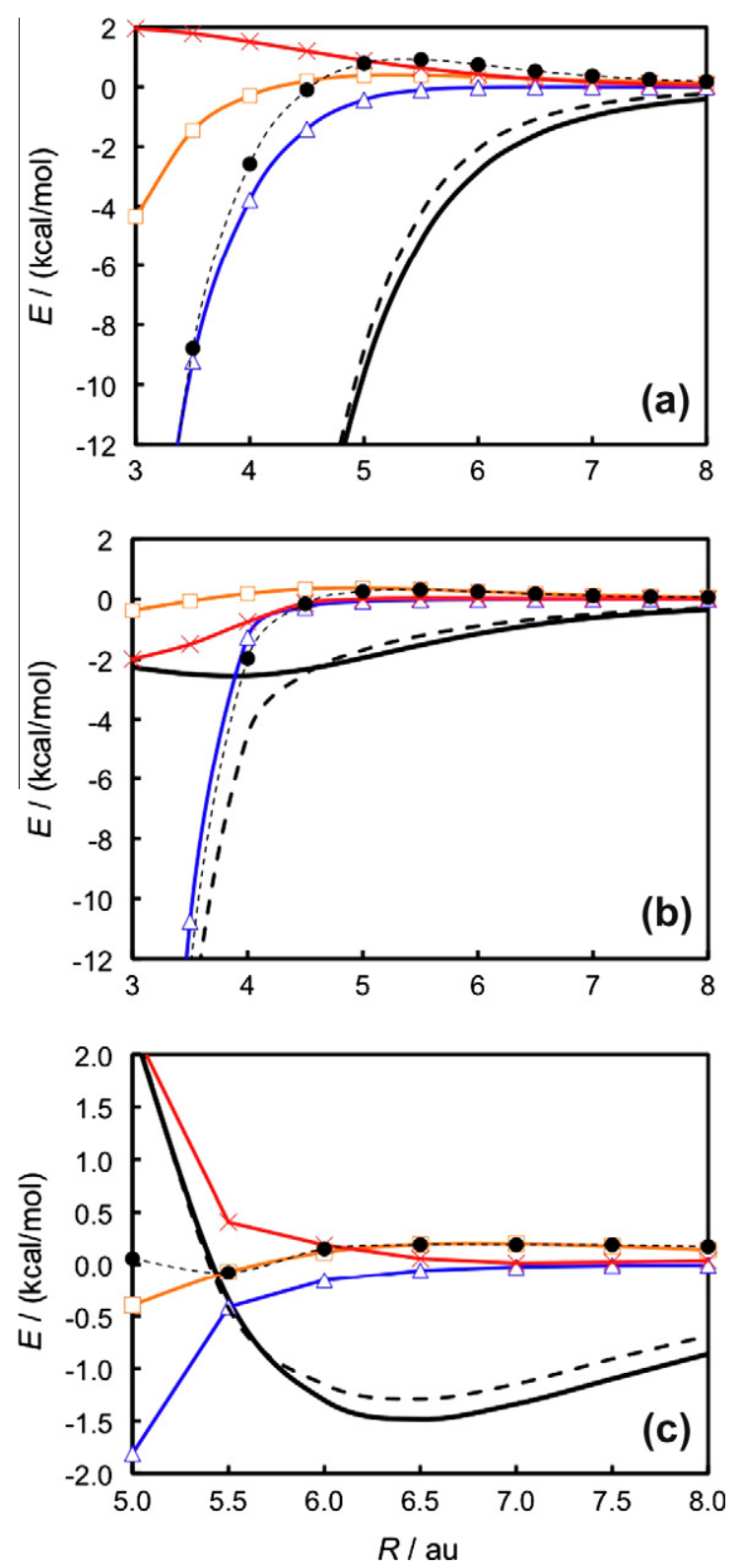

Fig. 1. One-dimensional correction potentials for the (a) association channel $\left(R=R_{C^{\prime} \mathrm{O}}\right)$, (b) abstraction channel $\left(R=R_{C^{\prime} \mathrm{H}}\right)$, and (c) saddle point region $\left(R=R_{\mathrm{C}^{\prime} \mathrm{Q}}\right)$, where $Q$ is the midpoint of $C-O$ in the methoxy fragment and $C^{\prime}$ is the $C$ atom in the $\mathrm{CH}_{3}$ fragment. In each panel, (thick solid line) labels the uncorrected ab initio energies, (orange open squares, solid line) labels the difference between the CBS and uncorrected energies, (blue open triangles, solid line) labels the difference between the energies of the relaxed fragment geometries and uncorrected energies of the unrelaxed fragments, (red $\times$, solid line) labels the difference between the zero point energies of relaxed and unrelaxed fragments, (filled black circles, thin dotted line) labels the sum of the three previous difference energies, and (thick dashed black line) labels the corrected energies. (For interpretation of the references to color in this figure legend, the reader is referred to the web version of this article.)

$\bar{V}_{\mathrm{ab}}=\sum_{i} V_{\mathrm{ab}}\left(R_{\mathrm{C}^{\prime} \mathrm{Hi}}\right) 1 / 2\left(1+\tanh \left(\left(60^{\circ}-\phi_{i}\right) / 5^{\circ}\right)\right)$,

where the hyperbolic tangent weights the contributions from the three $\mathrm{C}^{\prime}-\mathrm{H}$ distances as a function of the $\mathrm{C}^{\prime}-\mathrm{C}-\mathrm{H}_{i}$ angles $\phi_{i}$. The total correction is given by

$V_{\text {cor }}=V_{\mathrm{sp}}+\left(V_{\mathrm{as}}-V_{\mathrm{sp}}\right) F_{1}(s)+\left(\bar{V}_{\mathrm{ab}}-V_{\mathrm{sp}}\right) F_{2}(s)$,

where $F_{x}$ are hyperbolic tangent switching functions with range parameters of $5^{\circ}$ and centers of $80^{\circ}\left(F_{1}\right)$ or $100^{\circ}\left(F_{2}\right)$, and $s$ is a progress variable defined as the $C^{\prime}-Q-O$ angle.
A number of other simple strategies for combining the three one-dimensional corrections were also considered. These alternatives provided very similar results in the RDT calculations. A more detailed discussion of these higher level multichannel "one-dimensional" corrections will be presented in a future paper.

\subsection{Trajectory calculations}

The previous study on $\mathrm{CH}_{3} \mathrm{CHO}$ [18] outlined an RDT approach for calculating the dissociative and roaming fluxes. This approach requires an appropriate PES in the reduced dimensions that describe transitional modes of motion along either the dissociation or roaming pathway. Using the CASPT2/aug-cc-pVDZ based IMLS fitted PES for the transitional mode motions in $\mathrm{CH}_{3} \mathrm{OCH}_{3}$, we have implemented that same procedure here. Briefly we calculated RDT dynamics on the corrected IMLS PES to estimate contributions to the reactive fluxes (reactive numbers of states) between the reactants and different products. This is accomplished by the propagation of rigid-body trajectories forward and backward on an appropriately weighted micro-canonical ensemble of configurations on a dividing surface separating reactants and different products. The rigid-body trajectories only explicitly involve the transitional degrees of freedom. The remaining conserved degrees of freedom are treated within a vibrationally adiabatic framework as part of the corrections to the PES described earlier. These corrections incorporate, as a function of the transitional degrees of freedom, the change in the vibrationally adiabatic zero-point energy from asymptotic values of the conserved modes. The trajectory results can be represented as micro-canonical statistical rates, trajectory-corrected for recrossing for both roaming and dissociation.

As discussed above, the trajectories are started on a dividing surface and used to correct the statistical flux for recrossing. In principle, any dividing surface that separates regions of phase space for the dissociative and the roaming process will do, although less optimal dividing surfaces lead to large amounts of recrossing and therefore large numbers of long-lived trajectories are required to converge the dissociative and roaming flux within small statistical uncertainties. The highly unsymmetrical dividing surfaces about the HCO fragment reported for $\mathrm{CH}_{3} \mathrm{CHO}$ are not appropriate here for the highly symmetrical $\mathrm{OCH}_{3}$ fragment. Multiple choices for the dividing surfaces were tested yielding comparable results (although in general requiring different numbers of trajectories). Most of the results used a sphere approximately centered on the $\mathrm{C}$ and another sphere approximately centered on the $\mathrm{O}$ in the $\mathrm{OCH}_{3}$. A plane perpendicular to the $\mathrm{C}-\mathrm{O}$ bond and intersecting the $\mathrm{C}-\mathrm{O}$ bond near the center of mass of $\mathrm{OCH}_{3}$ is then used to create two regions: a truncated sphere on the $\mathrm{O}$ side from which all dissociative and roaming processes start and a truncated sphere on the $C$ side within which all roaming and abstraction processes end. The perpendicular plane nearly passes through the roaming saddle point. With this dividing surface, the RDT method required from 500 to 10,000 trajectories to converge the flux to typically a few percent for dominant processes. The flux of a less dominant process, which might be several orders of magnitude less than the flux of the dominant process, was converged within $\sim 10 \%$.

The IMLS method [18] of fitting a PES results in global expansions of the PES about each ab initio point included in the fit. To evaluate the energy at a given point on the IMLS PES, the value of each expansion is assigned a weight [as in Eq. (E1)] that is a function of how near in the distance metric [Eq. (E6)] the ab initio point is to the given point. In the case of $\mathrm{CH}_{3} \mathrm{OCH}_{3}$, this approach would be unwieldy if all 437 basis functions expanded about each of 4366 ab initio points had to be evaluated to determine an energy on the IMLS PES. Instead, a neighbor-list scheme was used in which a ranked list of nearby $a b$ initio points was established with the 
evaluations terminated when the weight of the last point is some input cutoff fraction of the accumulated sum. The weighted summation of the value of the global expansion of each ab initio point on the list gives the IMLS energy. As will be discussed in a later paper, there are approximations to the ranked list that avoid calculating the full distance metric for each of 4366 ab initio points for every IMLS evaluation. Aggressive application of these approximations and the cutoff fraction can speed up the average IMLS evaluation time in trajectory studies by more than an order of magnitude, but at the price of an increased drift in the energy conservation of the trajectory. Convergence tests of RDT flux established the values of the cutoff fraction and parameters controlling approximations to the ranked list. The resulting rms error in trajectory energy conservation for any trajectory run was always below $0.02 \mathrm{kcal} / \mathrm{mol}$. The flux determined from these trajectory runs was within the statistical error bars of flux calculated from faster, preliminary trajectory runs with an order of magnitude larger rms error. If run on a single processor, the resulting RDT trajectory calculations took between a day and a week depending on the energy (low energy trajectories take much longer). Production level trajectory runs were generally done on eight processors at a time to shorten turnaround to no more than a few days.

\subsection{Kinetics calculations}

The pressure dependence of the experiments is represented with one-dimensional master equation calculations [37] in energy employing an exponential down collisional energy transfer model and Lennard-Jones collision frequencies. The average downward energy transfer is taken to be $100(T / 300)^{0.85} \mathrm{~cm}^{-1}$. This expression employs a standard temperature dependence [38] and is normalized to yield rate coefficients that are in good agreement with the experimental measurements of the overall decomposition rate.

The reactive fluxes for channels (R1) and (R2) are obtained from the trajectory calculations with the IMLS fitted ab initio potential energy surface. The final results include the correction, $V_{\text {cor }}$. The reactive fluxes for the channels with well-defined saddle points are obtained from tunneling corrected conventional transition state theory employing rigid rotor harmonic oscillator assumptions for the energy levels. The two methyl rotors in DME are treated as separable one-dimensional hindered rotors, while the remaining vibrational modes were treated as harmonic oscillators. The $\operatorname{CCSD}(\mathrm{T}) /$ aug-cc-pVDZ calculated rovibrational properties were employed in these flux analyses.

\section{Results and discussion}

\subsection{Experimental results}

\subsubsection{High temperature/dilute experiments}

Two sets of experiments were performed in the present work. The first set utilized very dilute mixtures $(<1 \mathrm{ppm})$ of $\mathrm{CH}_{3} \mathrm{OCH}_{3}$ thereby suppressing secondary reactions that deplete $[\mathrm{H}]$. This suppression allowed direct measurements of the branching ratios to the $\mathrm{C}-\mathrm{O}$ bond fission channel through (R1). In these experiments, $\mathrm{H}-$ atoms were measured from the subsequent instantaneous $\mathrm{CH}_{3} \mathrm{O}$ radical decomposition from (R1) to give $\mathrm{H}+\mathrm{CH}_{2} \mathrm{O}$. Fifty experiments were performed that span a temperature range, 1406-1764 K, and pressure range, $0.20-1.25 \mathrm{~atm}$. Figure 2 shows a typical H-atom profile at $T=1572 \mathrm{~K}$ using $\left[\mathrm{CH}_{3} \mathrm{OCH}_{3}\right]_{0}=1.15 \times 10^{12}$ molecules $\mathrm{cm}^{-3}$, yielding $[\mathrm{H}]_{\infty}=9.05 \times 10^{11}$ atoms $\mathrm{cm}^{-3}$. The simulated results using the mechanism given in Table 1 are shown as the solid black line. The long dashed lines show variations in the overall decomposition rate constant, $k_{\text {total }}$, by $\pm 40 \%$, and the dotted lines show variations of \pm 0.1 in the branching ratio giving $\mathrm{H}$-atoms, $\mathrm{BR}_{1}=k_{1} / k_{\text {total }}$. The simulations were performed using the SENKIN [39] suite of

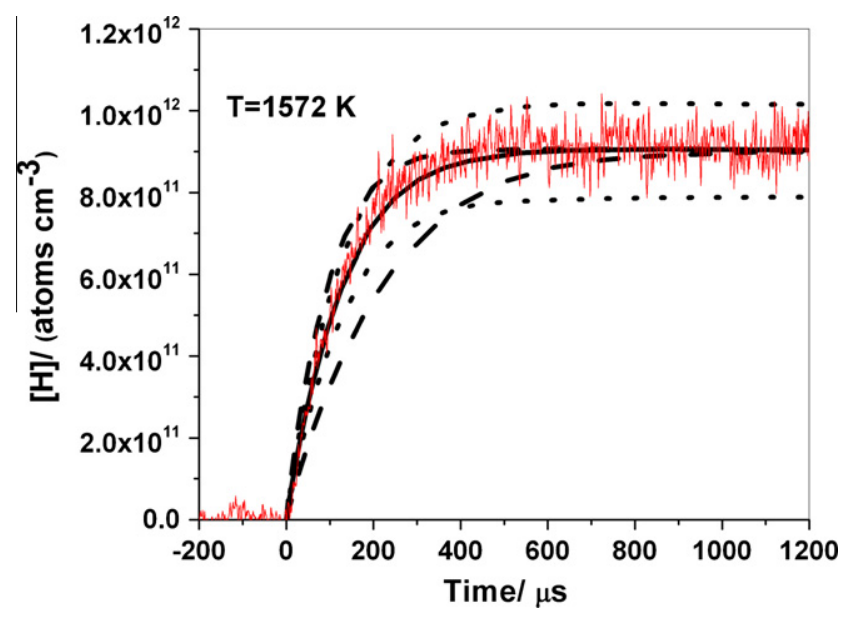

Fig. 2. $[\mathrm{H}]$ profile at $1572 \mathrm{~K}$. The solid line is a fit over the entire time range using the mechanism in Table 1 with $k_{1}+k_{2}=8000 / \mathrm{s}$ and $\mathrm{BR}_{1}=0.79$. The dashed lines represent changes in $k_{1}+k_{2}$ by $\pm 40 \%$ with $\mathrm{BR}_{1}=0.79$. The dotted lines represent changes in $\mathrm{BR}_{1}$ by \pm 0.1 with $k_{1}+k_{2}$ fixed at $8000 \mathrm{~s}^{-1}$. The conditions for the experiment at $T_{5}=1572 \mathrm{~K}$ are $P_{1}=10.95 \mathrm{Torr}, M_{s}=2.506, \rho_{5}=2.103 \times 10^{18}$ molecules $\mathrm{cm}^{-3},\left[\mathrm{CH}_{3} \mathrm{OCH}_{3}\right]_{0}=1.15 \times 10^{12}$ molecules $\mathrm{cm}^{-3}$.

programs in the CHEMKIN package. An example sensitivity plot is shown in Fig. 3 for Fig. 2 experiment where it is seen that the profile depends only on $k_{1}$ and $k_{2}$; i.e., secondary reactions involving $\mathrm{H}$ are completely unimportant since the maximum value of $[\mathrm{H}]$ is so low, indicating that first-order analysis is appropriate. The normalized sensitivity coefficients are defined as $\partial \ln [\mathrm{H}] / \partial \ln k_{i}$ where $[\mathrm{H}]$ is the $\mathrm{H}$-atom concentration and $k_{i}$ the rate constant for reaction $i$. Hence, the present results are a direct measure of dissociation.

First-order analysis gives the simple closed form result

$[\mathrm{H}]_{t}=\left\{k_{1}\left[\mathrm{CH}_{3} \mathrm{OCH}_{3}\right]_{0} /\left(k_{1}+k_{2}\right)\right\} \times\left\{1-\exp \left(-\left(k_{1}+k_{2}\right) t\right)\right\}$,

where $[\mathrm{H}]_{\infty}=k_{1}\left[\mathrm{CH}_{3} \mathrm{OCH}_{3}\right]_{0} /\left(k_{1}+k_{2}\right)$ and $\mathrm{BR}_{1}=k_{1} /\left(k_{1}+k_{2}\right)$. For the data shown in Fig. 2, inspection shows that $\mathrm{BR}_{1}=9.05 \times 10^{11}$ / $1.15 \times 10^{12}=0.79$. We have determined the total decomposition rate constant, $k_{t}=k_{1}+k_{2}$, from temporal profiles like that shown in Fig. 2 using Eq. (E9) by adjusting $k_{t}$ and $\mathrm{BR}_{1}$ to obtain a good fit to the experimental profile. Subsequently, we determine $k_{1}$ and $k_{2}$ from the measured $\mathrm{BR}_{1}$ for the same experiment. The results are given in Table 2 along with the inferred $\mathrm{BR}_{2}\left(=1-\mathrm{BR}_{1}\right)$. Using these first order analyses for $k_{1}$ and $k_{2}$ in Table 1 mechanism to simulate the profiles, the same results are recovered as those using Eq. (E9). This confirms the observations from the sensitivity analysis of Fig. 3 that first-order analysis is appropriate for all the experiments reported in Table 2 .

The decomposition rate constants at various densities are shown in Figs. 4 and 5 as Arrhenius plots. The major decomposition pathway is reaction (R1), as assumed in all previous work. However, we find significance to reaction (R2) that is entirely due to the roaming mechanism. As discussed in the theory results below, all other channels are kinetically insignificant contributors for the conditions of the present experiments. The temperature and density dependences of $\mathrm{BR}_{2}$ are shown in Fig. 6. A comparison of the highest and lowest density data shows that $\mathrm{BR}_{2}$ tends to vary with $\rho$. Also, it appears that $\mathrm{BR}_{2}$ tends to decrease with increasing temperature. Overall, for the full temperature and pressure range of the experiments, the mean value for $\mathrm{BR}_{2}$ is $0.19 \pm 0.07$. The value of $\mathrm{BR}_{2}$ and its $T$ and $\rho$ dependence will be addressed theoretically in Section 4.2 .

\subsubsection{Low temperature/more concentrated experiments}

The second set of experiments used more concentrated mixtures (5-10 ppm) that are similar to those from the recent H-ARAS 
Table 1

Mechanism for $\mathrm{CH}_{3} \mathrm{OCH}_{3}$ Decomposition and $\mathrm{H}+\mathrm{CH}_{3} \mathrm{OCH}_{3} \cdot{ }^{\text {a }}$

\begin{tabular}{|c|c|c|c|}
\hline 1 & $\mathrm{CH}_{3} \mathrm{OCH}_{3} \rightarrow \mathrm{CH}_{2} \mathrm{O}+\mathrm{H}+\mathrm{CH}_{3}$ & $k_{1}=$ to be fitted & [Present] \\
\hline 2 & $\mathrm{CH}_{3} \mathrm{OCH}_{3} \rightarrow \mathrm{CH}_{4}+\mathrm{CH}_{2} \mathrm{O}$ & $k_{2}=$ to be fitted & [Present] \\
\hline 3 & $\mathrm{H}+\mathrm{CH}_{3} \mathrm{OCH}_{3} \rightarrow \mathrm{CH}_{3} \mathrm{OCH}_{2}+\mathrm{H}_{2}$ & $k_{3}=$ to be fitted & [Present] \\
\hline 4 & $\mathrm{CH}_{3} \mathrm{OCH}_{2} \rightarrow \mathrm{CH}_{3}+\mathrm{CH}_{2} \mathrm{O}$ & $k_{4}=4.45 \times 10^{14} T^{-0.22} \exp (-13,702 \mathrm{~K} / T)$ & {$[46]$} \\
\hline 5 & $\mathrm{CH}_{2} \mathrm{O}+\mathrm{Kr} \rightarrow \mathrm{HCO}+\mathrm{H}+\mathrm{Kr}$ & $k_{5}=1.019 \times 10^{-8} \exp (-38,706 \mathrm{~K} / T)$ & [20] \\
\hline 6 & $\mathrm{CH}_{2} \mathrm{O}+\mathrm{Kr} \rightarrow \mathrm{H}_{2}+\mathrm{CO}+\mathrm{Kr}$ & $k_{6}=4.658 \times 10^{-9} \exp (-32,110 \mathrm{~K} / T)$ & {$[20]$} \\
\hline 7 & $\mathrm{HCO}+\mathrm{Kr} \rightarrow \mathrm{H}+\mathrm{CO}+\mathrm{Kr}$ & $k_{7}=6.00 \times 10^{-11} \exp (-7722 \mathrm{~K} / T)$ & {$[47]$} \\
\hline 8 & $\mathrm{CH}_{3}+\mathrm{CH}_{3} \rightarrow \mathrm{C}_{2} \mathrm{H}_{6}$ & $k_{8}=f(\rho, T)$ & {$[48]$} \\
\hline 9 & $\mathrm{CH}_{3}+\mathrm{CH}_{3} \rightarrow \mathrm{C}_{2} \mathrm{H}_{4}+2 \mathrm{H}$ & $k_{9}=5.26 \times 10^{-11} \exp (-7392 \mathrm{~K} / T)$ & {$[28]$} \\
\hline 10 & $\mathrm{CH}_{3}+\mathrm{CH}_{3} \mathrm{OCH}_{3} \rightarrow \mathrm{CH}_{4}+\mathrm{CH}_{3} \mathrm{OCH}_{2}$ & $k_{10}=4.45 \times 10^{-23} T^{3.78} \exp (-4847 \mathrm{~K} / T)$ & [3] \\
\hline
\end{tabular}

${ }^{\text {a }}$ All unimolecular rate constants are in $\mathrm{s}^{-1}$ and bimolecular rate constants are in $\mathrm{cm}^{3}$ molecule $\mathrm{s}^{-1}$.

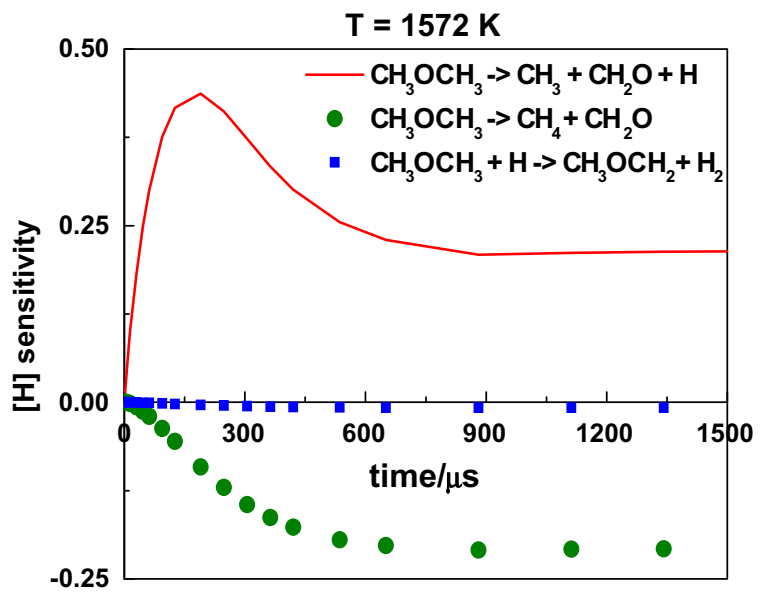

Fig. 3. H-atom sensitivity analysis for the $1572 \mathrm{~K}$ profile shown in Fig. 2 using the full reaction mechanism scheme. The three most sensitive reactions are shown in the inset.

study of Fernandes et al. [9]. Under these conditions, secondary reactions begin to perturb the $[\mathrm{H}]$ profile, particularly the abstraction reaction,

$\mathrm{H}+\mathrm{CH}_{3} \mathrm{OCH}_{3} \rightarrow \mathrm{H}_{2}+\mathrm{CH}_{3} \mathrm{OCH}_{2}$

Hence, the H-atom yields at long times are suppressed. Consequently, these experiments permitted simultaneous measurements for (R1) and (R3) to be made. Seventeen experiments were performed spanning a temperature range, 1149-1465 K. Figure 7 shows a typical $\mathrm{H}$-atom profile from an experiment at $1248 \mathrm{~K}$ using $\left[\mathrm{CH}_{3} \mathrm{OCH}_{3}\right]_{0}=5.38 \times 10^{13}$ molecules $\mathrm{cm}^{-3}$. The corresponding sensitivity analysis, Fig. 8 , clearly shows that the two reactions that determine the profile in Fig. 7 are indeed only R1 and R3. There is little or no sensitivity to $\mathrm{R} 2$. Initial values of $k_{1}$ for simulating the profile in Fig. 7 are obtained by extrapolation of the results in Table 2 to lower temperatures by means of an Arrhenius expression for each particular reflected shock density range. Initial values of $k_{3}$ are taken from the work of Takahashi et al. [21]. The black solid line is a fit to the profile in Fig. 7 using the mechanism in Table 1 with final optimized values of $k_{1}$ (that matches the early rise time) and $k_{3}$ (that provides a best fit to the late time). The dashed lines are changes to $k_{3}$ by $\pm 50 \%$ and these significantly degrade the fit to the profile in comparison to the optimized value from modeling. The experimental conditions as well as the optimized $k_{1}$ and $k_{3}$ values obtained from the simulations are summarized in Table 3. With these experimental results, the rate constant database for (R1) now spans the temperature range from 1149 to $1764 \mathrm{~K}$.

The abstraction rate constants for (R3) over the temperature range $1149-1465 \mathrm{~K}$ in Table 3 can be represented by an Arrhenius expression in units, $\mathrm{cm}^{3}$ molecule $\mathrm{e}^{-1} \mathrm{~s}^{-1}$,

$k_{3}=2.147 \times 10^{-9} \exp (-5914 / T)$
At the one standard deviation level, the present experiments are within $\pm 31 \%$ of the line determined from Eq. (E10). Combining the present data (Table 3 ) for reaction (R3) with the data of Takahashi et al. [21] and the lower- $T$ results of Tranter and Walker [40], Faubel et al. [41], Lee et al. [42], and Meagher et al. [43], rate constants have been evaluated over the temperature range, $273-1465 \mathrm{~K}$, to give

$k_{3}=6.54 \times 10^{-24} T^{4.13} \exp (-896 / T) \mathrm{cm}^{3}$ molecule ${ }^{-1} \mathrm{~s}^{-1}$

This evaluation, Eq. (E11), is within $\pm 9 \%$ of the Arrhenius expression derived from the present data, Eq. (E10), over the temperature range of overlap. A plot of Eq. (E11) and the data from which it was derived is shown in Fig. 9. We have chosen to use the lower$T$ data of Meagher et al. [43] and Faubel et al. [41] for the evaluation despite the uncertainties in these measurements (due to stoichiometric corrections employed to obtain rate constants). It is evident that the room- $T$ measurements of Slemr and Warneck [44] must be in error [42] and consequently they were ignored in the present evaluation. The data of Fernandes et al. [9] was also not included in this evaluation since they assumed a $T$-independent value for $k_{3}$ in order to extract $k_{1}$ values.

The theoretical predictions of Takahashi et al. [21] appear to be in better agreement with the lower- $T$ measurements of Meagher et al. [43] than the more direct resonance-fluorescence measurements of Lee et al. [42]. The more rigorous $\mathrm{QCISD}(\mathrm{T}) / 6-311+\mathrm{G}(3 \mathrm{df}, 3 \mathrm{pd}) / /$ MP2 $/ 6-311+G(d, p)$ based variational TST based theoretical predictions of Wu et al. [45] are in reasonable agreement with the low- $T$ data, but systematically overpredict the abstraction rate constants for (R3) by a factor of $2-3$ at high- $T(>500 \mathrm{~K})$.

\subsection{Theoretical results}

\subsection{1. $\mathrm{CH}_{3}+\mathrm{CH}_{3} \mathrm{O}$ interaction potential}

Contour diagrams illustrating the interaction of a rigid $\mathrm{CH}_{3}$ radical with a rigid $\mathrm{CH}_{3} \mathrm{O}$ radical are provided in Fig. 10 . The strongly attractive contours in the lower left and right portions of the plots illustrate the barrierless addition of the methyl radical to the $\mathrm{O}$ atom of methoxy from either the cis or trans sides of the in-plane $\mathrm{H}$-atom. This addition is barrierless for the full range of torsion angles. The attractive contours toward the upper left of the plots illustrate the barrierless approach of the methyl radical toward the H-atom in methoxy that is in the plane of the plot. Similar barrierless paths exist for approach to the two out-of-plane $\mathrm{H}$-atoms. The $\mathrm{CH}_{3}+\mathrm{CH}_{3} \mathrm{O}$ abstraction reaction requires significant relaxation of the rigid fragment structures. As a result, the minimum potential for the rigid approach to the $\mathrm{H}$-atom is only about $3 \mathrm{kcal} / \mathrm{mol}$ (cf. Fig. 10). Inclusion of the relaxation correction dramatically changes the interaction potential in the abstraction region, as illustrated in Fig. 11.

The estimated RMS and mean errors for the IMLS fit to the potential ( 0.28 and $0.13 \mathrm{kcal} / \mathrm{mol}$, respectively) provide measures of the accuracy of the fit. However, it is not clear to what extent these 
Table 2

Higher- $T$ rate data: $\mathrm{CH}_{3} \mathrm{OCH}_{3} \rightarrow \mathrm{CH}_{3}+\mathrm{H}+\mathrm{CH}_{2} \mathrm{O}$ and $\mathrm{CH}_{3} \mathrm{OCH}_{3} \rightarrow \mathrm{CH}_{4}+\mathrm{CH}_{2} \mathrm{O}$

\begin{tabular}{|c|c|c|c|c|c|c|c|}
\hline$P_{1}^{\mathrm{a}}$ (Torr) & $M_{s}^{\mathrm{b}}$ & $\rho_{5}\left(10^{18} \mathrm{~cm}^{-3}\right)^{\mathrm{c}}$ & $T_{5}(\mathrm{~K})^{\mathrm{c}}$ & $P_{5}(\text { Torr })^{\mathrm{c}}$ & $k_{1}{ }^{\mathrm{d}}$ & $k_{2}{ }^{\mathrm{d}}$ & $\mathrm{BR}_{2}^{\mathrm{e}}$ \\
\hline \multicolumn{8}{|c|}{$\mathrm{X}_{\mathrm{CH} 3 \mathrm{OCH} 3}=1.111 \times 10^{-6}$} \\
\hline 5.94 & 2.580 & 1.173 & 1659 & 201.6 & 8910 & 2090 & 0.19 \\
\hline 5.92 & 2.549 & 1.156 & 1622 & 194.2 & 8200 & 1800 & 0.18 \\
\hline 5.92 & 2.502 & 1.135 & 1568 & 184.3 & 3666 & 1034 & 0.22 \\
\hline 5.89 & 2.495 & 1.126 & 1560 & 181.9 & 3080 & 920 & 0.23 \\
\hline 5.86 & 2.357 & 1.056 & 1406 & 153.8 & 547.5 & 202.5 & 0.27 \\
\hline 5.91 & 2.407 & 1.090 & 1461 & 165.0 & 1184 & 416 & 0.26 \\
\hline 5.95 & 2.438 & 1.112 & 1495 & 172.2 & 1848 & 552 & 0.23 \\
\hline 5.91 & 2.650 & 1.196 & 1743 & 215.9 & 15,840 & 2160 & 0.12 \\
\hline 5.92 & 2.561 & 1.161 & 1636 & 196.7 & 8610 & 1890 & 0.18 \\
\hline 5.93 & 2.616 & 1.186 & 1701 & 209.0 & 12,600 & 2400 & 0.16 \\
\hline \multicolumn{8}{|c|}{$\mathrm{X}_{\mathrm{CH} 3 \mathrm{OCH} 3}=5.469 \times 10^{-7}$} \\
\hline 10.91 & 2.459 & 2.056 & 1519 & 323.5 & 2464 & 736 & 0.23 \\
\hline 10.95 & 2.470 & 2.073 & 1531 & 328.7 & 2470 & 780 & 0.24 \\
\hline 10.92 & 2.438 & 2.040 & 1495 & 315.9 & 1312.5 & 437.5 & 0.25 \\
\hline 10.87 & 2.452 & 2.043 & 1511 & 319.8 & 2926 & 874 & 0.23 \\
\hline 10.91 & 2.520 & 2.107 & 1589 & 346.8 & 5197.5 & 1552.5 & 0.23 \\
\hline 10.79 & 2.593 & 2.141 & 1674 & 371.2 & 13,280 & 2720 & 0.17 \\
\hline 10.88 & 2.578 & 2.147 & 1657 & 368.5 & 8910 & 2090 & 0.19 \\
\hline 10.87 & 2.523 & 2.101 & 1592 & 346.5 & 6560 & 1440 & 0.18 \\
\hline 10.95 & 2.459 & 2.064 & 1519 & 324.7 & 2618 & 782 & 0.23 \\
\hline 10.95 & 2.506 & 2.103 & 1572 & 342.4 & 6320 & 1680 & 0.21 \\
\hline \multicolumn{8}{|c|}{$\mathrm{X}_{\mathrm{CH} 3 \mathrm{OCH} 3}=1.111 \times 10^{-6}$} \\
\hline 10.93 & 2.668 & 2.225 & 1764 & 406.5 & 19,350 & 3150 & 0.14 \\
\hline 10.84 & 2.598 & 2.154 & 1680 & 374.8 & 14,580 & 3420 & 0.19 \\
\hline 10.92 & 2.608 & 2.178 & 1692 & 381.7 & 14,000 & 3500 & 0.20 \\
\hline 10.95 & 2.519 & 2.113 & 1587 & 347.3 & 5304 & 1496 & 0.22 \\
\hline 10.89 & 2.442 & 2.038 & 1500 & 316.6 & 2485 & 1015 & 0.29 \\
\hline \multicolumn{8}{|c|}{$\mathrm{X}_{\mathrm{CH} 3 \mathrm{OCH} 3}=5.469 \times 10^{-7}$} \\
\hline 15.91 & 2.406 & 2.927 & 1458 & 442.0 & 1005 & 495 & 0.33 \\
\hline 15.90 & 2.552 & 3.090 & 1620 & 518.5 & 9000 & 3000 & 0.25 \\
\hline 15.84 & 2.545 & 3.071 & 1612 & 512.8 & 8625 & 2875 & 0.25 \\
\hline 15.75 & 2.507 & 3.012 & 1567 & 488.9 & 5810 & 1190 & 0.17 \\
\hline 15.88 & 2.494 & 3.023 & 1554 & 486.6 & 2736 & 1064 & 0.28 \\
\hline 15.85 & 2.419 & 2.931 & 1472 & 446.9 & 1190 & 560 & 0.32 \\
\hline 15.94 & 2.455 & 2.990 & 1512 & 468.3 & 1988 & 812 & 0.29 \\
\hline 15.82 & 2.538 & 3.060 & 1604 & 508.4 & 9960 & 2040 & 0.17 \\
\hline 15.98 & 2.499 & 3.047 & 1560 & 492.4 & 4140 & 1610 & 0.28 \\
\hline \multicolumn{8}{|c|}{$\mathrm{X}_{\mathrm{CH} 3 \mathrm{OCH} 3}=2.628 \times 10^{-7}$} \\
\hline 15.97 & 2.521 & 3.070 & 1585 & 504.0 & 8280 & 720 & 0.08 \\
\hline 15.86 & 2.453 & 2.973 & 1509 & 464.7 & 2795 & 455 & 0.14 \\
\hline 15.89 & 2.385 & 2.898 & 1436 & 431.1 & 810 & 190 & 0.19 \\
\hline \multicolumn{8}{|c|}{$\mathrm{X}_{\mathrm{CH} 3 \mathrm{OCH} 3}=4.351 \times 10^{-7}$} \\
\hline 15.94 & 2.547 & 3.093 & 1614 & 517.1 & 7920 & 1080 & 0.12 \\
\hline 15.78 & 2.469 & 2.975 & 1526 & 470.2 & 3120 & 880 & 0.22 \\
\hline 15.72 & 2.546 & 3.049 & 1613 & 509.4 & 8602.5 & 647.5 & 0.07 \\
\hline 15.89 & 2.563 & 3.100 & 1633 & 524.4 & 10,005 & 1495 & 0.13 \\
\hline 15.88 & 2.421 & 2.939 & 1475 & 449.0 & 1760 & 440 & 0.20 \\
\hline \multicolumn{8}{|c|}{$\mathrm{X}_{\mathrm{CH} 3 \mathrm{OCH} 3}=2.628 \times 10^{-7}$} \\
\hline 30.72 & 2.435 & 5.604 & 1470 & 853.3 & 2400 & 600 & 0.20 \\
\hline 30.70 & 2.543 & 5.836 & 1589 & 960.5 & 19,200 & 800 & 0.04 \\
\hline 30.93 & 2.390 & 5.537 & 1421 & 815.0 & 1496 & 204 & 0.12 \\
\hline 30.64 & 2.500 & 5.733 & 1541 & 915.1 & 4895 & 605 & 0.11 \\
\hline 30.71 & 2.517 & 5.782 & 1560 & 934.3 & 9300 & 700 & 0.07 \\
\hline 30.59 & 2.437 & 5.585 & 1472 & 851.5 & 2666 & 434 & 0.14 \\
\hline 30.87 & 2.447 & 5.628 & 1482 & 863.9 & 2580 & 420 & 0.14 \\
\hline 30.47 & 2.415 & 5.513 & 1448 & 826.9 & 1344 & 256 & 0.16 \\
\hline
\end{tabular}

a The initial pressure.

b The error in measuring the Mach number, $M_{s}$, is typically $0.5-1.0 \%$ at the one standard deviation level.

c Quantities with the subscript 5 refer to the thermodynamic state of the gas in the reflected shock region.

${ }^{d}$ Rate constants: first order in $\mathrm{s}^{-1}$.

e $\mathrm{BR}_{2}=k_{2} /\left(k_{1}+k_{2}\right)$.

statistical errors affect the predicted kinetics. The relative error in the interaction energy in the transition state region of the potential is often a good measure of the relative error in the predicted kinetics. We have found in previous numerical simulations that, at least for modest errors, a given percent error in the minimum energy path potential roughly correlates with a corresponding percent error in the predicted rate coefficient.
One can obtain some sense of the relative errors via visual comparisons. Thus, we have presented a contour plot in Fig. 10b of a direct spline fit to a $100 \times 100$ grid of ab initio data. The strong similarity of the plots in Fig. 10a and b provides confidence in the IMLS fit. There are some visible discrepancies, particularly in the abstraction region of the potential, where the IMLS fit is too attractive. However, the error in that particular region is 


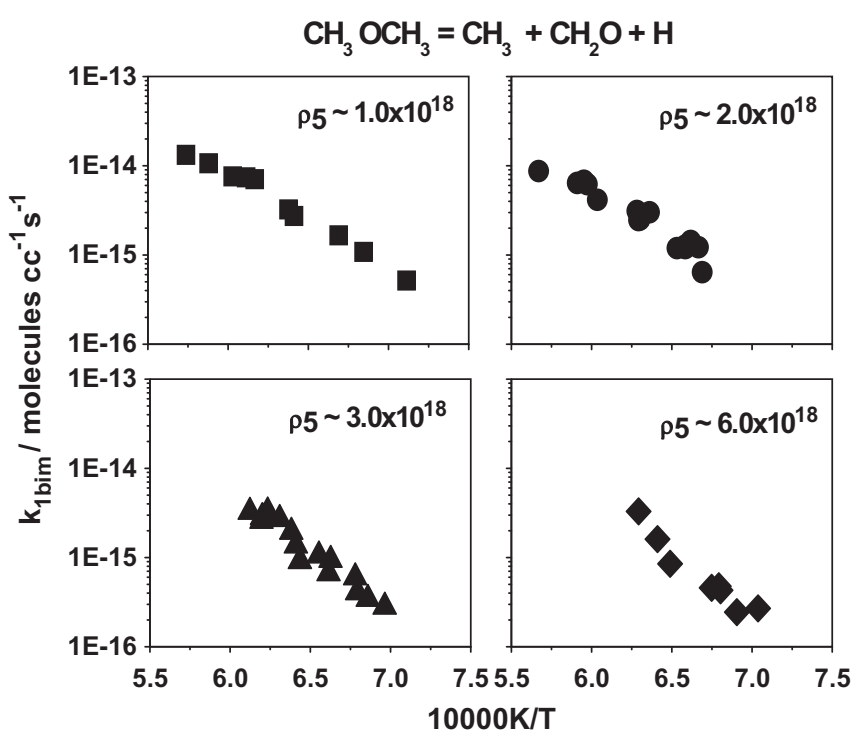

Fig. 4. Experimental bimolecular rate constants for $\mathrm{CH}_{3} \mathrm{OCH}_{3}+\mathrm{Kr} \rightarrow \mathrm{CH}_{3}+\mathrm{H}+$ $\mathrm{CH}_{2} \mathrm{O}+\mathrm{Kr}$. The four panels represent data obtained at four different reflected shock densities from $(1-6) \times 10^{18}$ molecules $\mathrm{cm}^{-3}$.

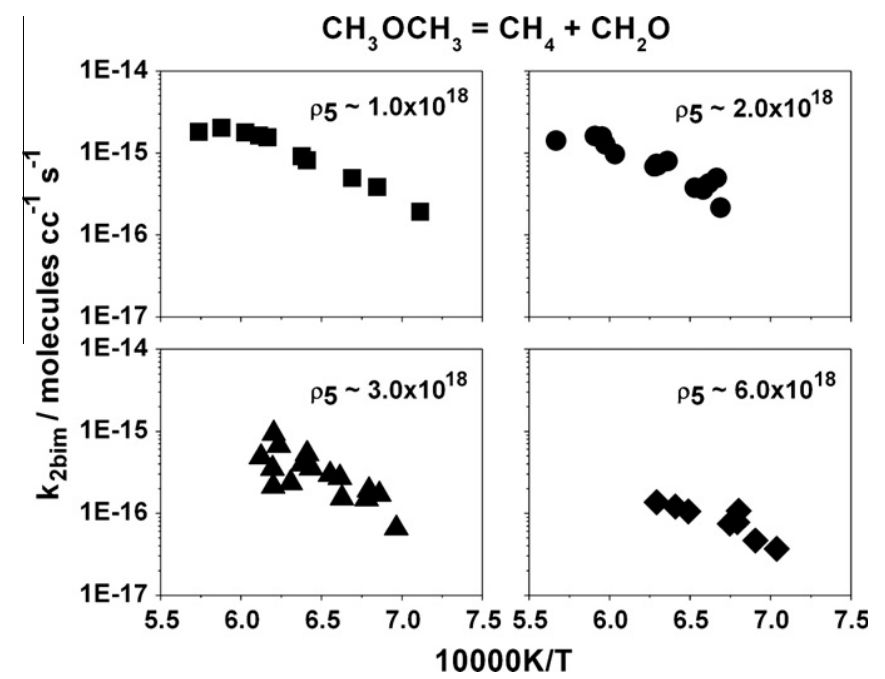

Fig. 5. Experimental bimolecular rate constants for $\mathrm{CH}_{3} \mathrm{OCH}_{3}+\mathrm{Kr} \rightarrow \mathrm{CH}_{4}+$ $\mathrm{CH}_{2} \mathrm{O}+\mathrm{Kr}$. The four panels represent data obtained at four different reflected shock densities from $(1-6) \times 10^{18}$ molecules $\mathrm{cm}^{-3}$.

ameliorated by the large 1D attractive correction that is applied (see Section 3.3) to that region (Fig. 11). The plots in Fig. 12, which illustrate the uncorrected IMLS fitted and directly calculated minimum energy pathway energies for both the addition and abstraction reactions, provide a quantitative indication of these discrepancies. The IMLS fit for the addition path is very accurate, but is in error by as much as $30 \%$ for the abstraction path.

On the corrected PES, the relative IMLS error along the abstraction reaction path is much smaller because of the size of the correction (see Fig. 11). However, where this IMLS error is largest in Fig. 12 is at $\mathrm{C}^{\prime}-\mathrm{H}$ distances near $4 \mathrm{a}_{0}$ where, as discussed previously, the correction itself is hard to accurately determine. Furthermore, the interpolation used in the correction is also not perfect as can be seen in Fig. 11 in the $1 \mathrm{kcal} / \mathrm{mol}$ dimple in the PES for approaching the $\mathrm{C}$ end of methoxy along its $\mathrm{C}-\mathrm{O}$ axis. A nearly identical dimple is found when the correction is added to the

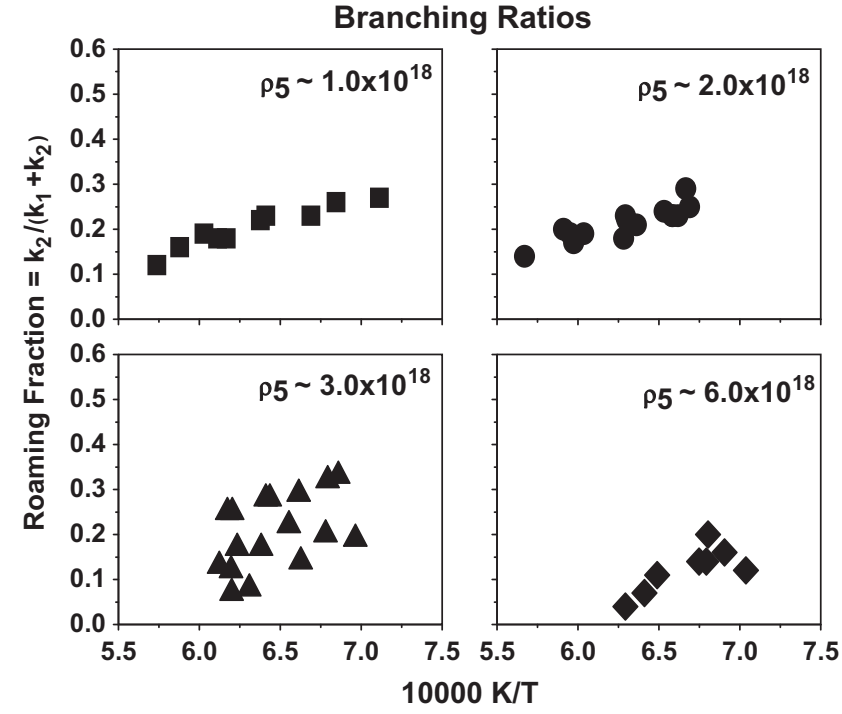

Fig. 6. Experimental branching ratios for reaction (R2) in the thermal decomposition of $\mathrm{CH}_{3} \mathrm{OCH}_{3}$. The four panels represent data obtained at four different reflected shock densities from $(1-6) \times 10^{18}$ molecules $\mathrm{cm}^{-3}$.

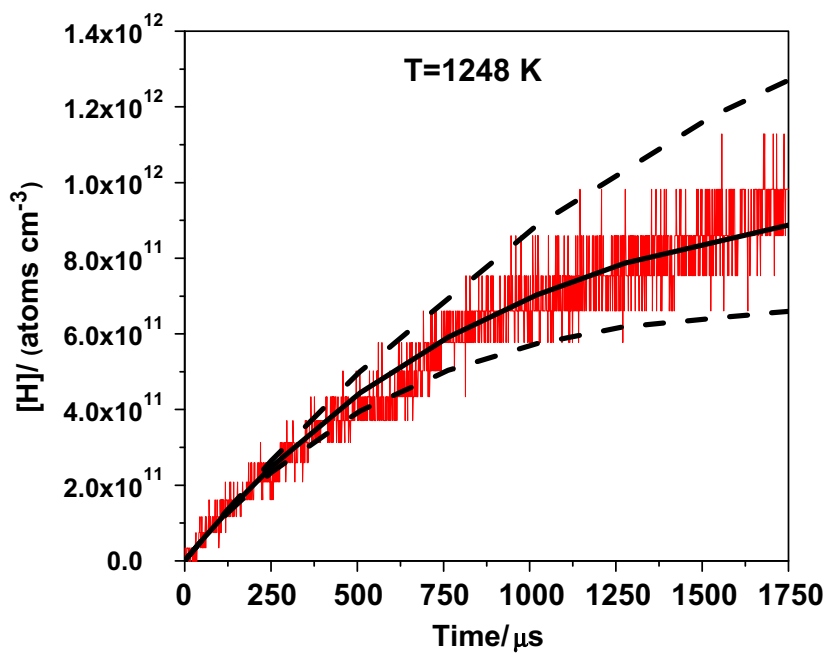

Fig. 7. $[\mathrm{H}]$ profile at $1248 \mathrm{~K}$. The solid line is a fit over the entire time range using the mechanism in Table 1 with the fitted values for $k_{1}$ and $k_{3}$ given in Table 3 . The dashed lines represent changes in $k_{3}$ by $\pm 50 \%$. The conditions for the experiment at $T_{5}=1248 \mathrm{~K}$ are $P_{1}=30.64 \mathrm{Torr}, M_{\mathrm{s}}=2.222, \rho_{5}=5.074 \times 10^{18}$ molecules $\mathrm{cm}^{-3}$ and $\left[\mathrm{CH}_{3} \mathrm{OCH}_{3}\right]_{0}=5.382 \times 10^{13}$ molecules $\mathrm{cm}^{-3}$.

spline fit of ab initio results in Fig. 10b. Since there is no trace of this feature in either uncorrected potential in Fig. 10, this is most likely a modest interpolation deficiency in the 1-D correction.

A final test of the IMLS fitting is provided by a comparison of VRC-TST predictions for the high pressure kinetics employing either directly determined ab initio energies or the IMLS fit. Such VRC-TST predictions for the $\mathrm{CH}_{3}+\mathrm{CH}_{3} \mathrm{O}$ addition and abstraction rate constants are plotted in Fig. 13. The two predictions for the addition rate coefficient are in remarkably good agreement, differing by only a few percent at most. These very modest deviations are largest at high temperature because at high energy the transition state moves in to slightly less than 5 bohr, while the IMLS surface is restricted to separations of $5 \mathrm{bohr}$ and greater. The deviations for the abstraction channel are somewhat greater, with the IMLS fit based results being as much as 1.28 times greater than 


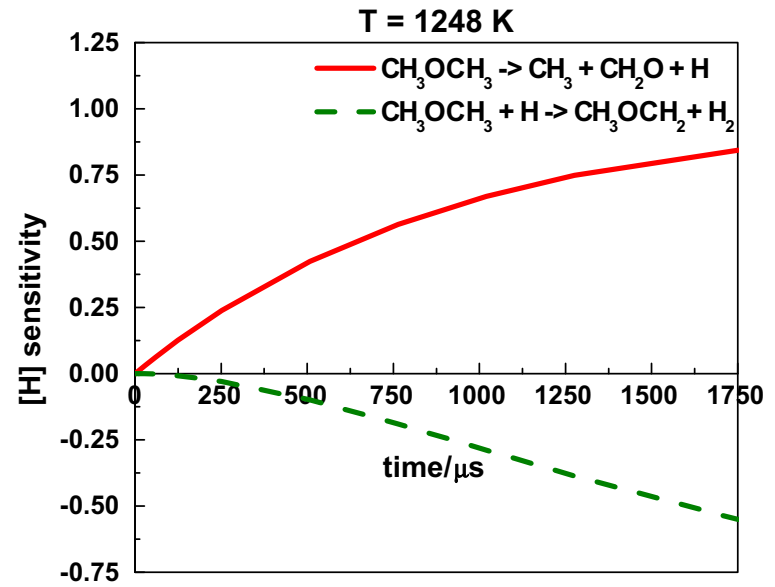

Fig. 8. H-atom sensitivity analysis for the $1248 \mathrm{~K}$ profile shown in Fig. 7 using the full reaction mechanism scheme in Table 1 . The two most sensitive reactions are shown in the inset.

Table 3

Lower- $T$ rate data: $\mathrm{CH}_{3} \mathrm{OCH}_{3} \rightarrow \mathrm{CH}_{3}+\mathrm{H}+\mathrm{CH}_{2} \mathrm{O}, \mathrm{H}+\mathrm{CH}_{3} \mathrm{OCH}_{3} \rightarrow \mathrm{H}_{2}+\mathrm{CH}_{3} \mathrm{OCH}_{2}$.

\begin{tabular}{|c|c|c|c|c|c|c|}
\hline$P_{1}^{\mathrm{a}}$ (Torr) & $M_{s}^{\mathrm{b}}$ & $\rho_{5}\left(10^{18} \mathrm{~cm}^{-3}\right)^{\mathrm{c}}$ & $T_{5}(\mathrm{~K})^{\mathrm{c}}$ & $P_{5}(\text { Torr })^{\mathrm{c}}$ & $k_{1}{ }^{\mathrm{d}}$ & $k_{3}{ }^{\mathrm{e}}$ \\
\hline \multicolumn{7}{|c|}{$\mathrm{X}_{\mathrm{CH} 3 \mathrm{OCH} 3}=5.259 \times 10^{-6}$} \\
\hline 10.96 & 2.257 & 1.883 & 1299 & 253.3 & 70 & $2.00(-11)$ \\
\hline 10.93 & 2.387 & 1.998 & 1439 & 297.7 & 750 & $3.50(-11)$ \\
\hline 10.92 & 2.254 & 1.874 & 1297 & 251.7 & 85 & $1.90(-11)$ \\
\hline 10.92 & 2.287 & 1.905 & 1332 & 262.8 & 130 & $2.25(-11)$ \\
\hline 10.91 & 2.416 & 2.026 & 1465 & 307.4 & 1300 & $5.00(-11)$ \\
\hline 10.82 & 2.201 & 1.806 & 1242 & 232.3 & 33 & $1.70(-11)$ \\
\hline 10.92 & 2.315 & 1.931 & 1361 & 272.2 & 280 & $3.00(-11)$ \\
\hline 10.87 & 2.338 & 1.943 & 1386 & 278.9 & 500 & $3.50(-11)$ \\
\hline \multicolumn{7}{|c|}{$\mathrm{X}_{\mathrm{CH} 3 \mathrm{OCH} 3}=5.259 \times 10^{-6}$} \\
\hline 15.91 & 2.284 & 2.776 & 1330 & 382.3 & 80 & $2.75(-11)$ \\
\hline \multicolumn{7}{|c|}{$\mathrm{X}_{\mathrm{CH} 3 \mathrm{OCH} 3}=1.061 \times 10^{-5}$} \\
\hline 15.95 & 2.277 & 2.774 & 1323 & 380.1 & 80 & $2.00(-11)$ \\
\hline 15.87 & 2.198 & 2.655 & 1242 & 341.5 & 17 & $1.70(-11)$ \\
\hline 15.83 & 2.273 & 2.748 & 1318 & 375.1 & 70 & $2.00(-11)$ \\
\hline 15.95 & 2.228 & 2.709 & 1273 & 357.1 & 26 & $1.90(-11)$ \\
\hline \multicolumn{7}{|c|}{$\mathrm{X}_{\mathrm{CH} 3 \mathrm{OCH} 3}=1.061 \times 10^{-5}$} \\
\hline 30.64 & 2.222 & 5.074 & 1248 & 655.8 & 21 & $2.00(-11)$ \\
\hline 30.87 & 2.225 & 5.120 & 1251 & 663.3 & 20 & $2.00(-11)$ \\
\hline 30.80 & 2.121 & 4.830 & 1149 & 574.7 & 2 & $1.50(-11)$ \\
\hline 30.68 & 2.150 & 4.890 & 1177 & 596.0 & 4 & $1.66(-11)$ \\
\hline
\end{tabular}

a The initial pressure.

b The error in measuring the Mach number, $M_{s}$, is typically $0.5-1.0 \%$ at the one standard deviation level.

${ }^{c}$ Quantities with the subscript 5 refer to the thermodynamic state of the gas in the reflected shock region.

${ }^{d}$ Rate constants: first order in $\mathrm{s}^{-1}$.

e Rate constants: bimolecular in $\mathrm{cm}^{3}$ molecule ${ }^{-1} \mathrm{~s}^{-1}$.

the direct ab initio based results. This modest overestimate of the abstraction rate coefficient is directly related to the overestimate of the attractiveness of the abstraction pathway.

The above predictions for the addition and abstraction rate coefficients include the "one-dimensional" correction to either the IMLS potential or the directly calculated rigid fragment ab initio energies. Beyond any imperfections in the correction, we have not considered the effect of either Jahn-Teller or spin-orbit splittings on the reactant partition functions. Thus, these predictions may be in considerable error in an absolute sense. Unfortunately, there do not appear to be any reliable experimental measurements of these rate coefficients. The consideration of such Jahn-Teller and spin-orbit splittings was deemed beyond the scope of the present analysis, particularly since their effect on

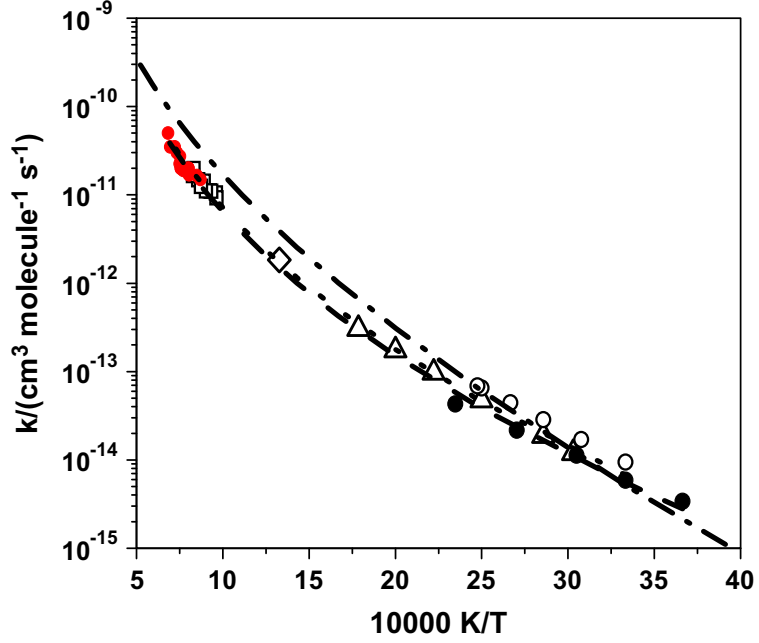

Fig. 9. Arrhenius plot of the $\mathrm{H}+\mathrm{CH}_{3} \mathrm{OCH}_{3}$ rate constants. (- - -) - three parameter evaluation, present work, Eq. (E11), (273-1465 K), (...) - Theory, Takahashi et al. [21], (298-1500 K), (-.-) - Wu et al. [45], (250-2000 K), ( $\diamond)-$ Tranter and Walker [40] (753 K), (O) - Meagher et al. [43] (300-404 K), ( $\Delta$ ) - Faubel et al. [41], (330$560 \mathrm{~K}),(\square)$ - Takahashi et al. [21], (1038-1208 K), (•) - Lee et al. [42], (273-426 K), (O) - present work, large concentration $\mathrm{CH}_{3} \mathrm{OCH}_{3}$ mixtures (Table 3), (1149$1465 \mathrm{~K})$.

the transition state partition functions will be greatly reduced. Correspondingly, their neglect should be ameliorated in our present overall focus on the dissociation rather than association process.

\subsubsection{Roaming pathway}

The structure of the saddle point for the roaming-radical pathway is shown in Fig. 14. The structure is of $C_{s}$ symmetry having a $\mathrm{CO}$ distance for the breaking $\mathrm{C}-\mathrm{O}$ bond of $3.3 \AA$ and a $\mathrm{CH}$ distance for the new $\mathrm{C}-\mathrm{H}$ bond of $2.5 \AA$. For reference, this saddle point correlates with coordinates of $\sim(-6,-1)$ in the contour plots of Fig. 10 and 11. The CASPT2 calculations predict this saddle point to lie $1.6 \mathrm{kcal} / \mathrm{mol}$ below the $\mathrm{CH}_{3} \mathrm{O}+\mathrm{CH}_{3}$ asymptote. For comparison, the uncorrected and corrected IMLS fits yield energies of 1.8 and $1.5 \mathrm{kcal} / \mathrm{mol}$, respectively, at the CASPT2 saddle point geometry.

An unusual feature of this reaction path is that the roaming methyl radical inverts, i.e., the face of the methyl that starts off bonded to the oxygen is not the same face that ends up bonded to the hydrogen. This inversion can be seen clearly in an animation of the IRC available as a web enhanced object (see Supplemental material). This inversion of a roaming methyl radical has been observed before in the decomposition of alkanes and has been explained using Orbital Phase Continuity Principle (OPCP) arguments [11].

\subsubsection{Competing pathways}

Four possible competing decomposition pathways were examined. These were as follows:

$$
\begin{aligned}
\mathrm{CH}_{3} \mathrm{OCH}_{3} & \rightarrow \mathrm{H}+\mathrm{CH}_{3} \mathrm{OCH}_{2} \\
& \rightarrow \mathrm{CH}_{3} \mathrm{OH} \cdots{ }^{1} \mathrm{CH}_{2} \rightarrow \mathrm{CH}_{3} \mathrm{OH}+{ }^{1} \mathrm{CH}_{2} \\
& \rightarrow \mathrm{CH}_{3} \mathrm{OCH}+\mathrm{H}_{2} \\
& \rightarrow \mathrm{CH}_{2} \mathrm{O}+\mathrm{CH}_{4}
\end{aligned}
$$

where (R7) refers to the possibility of a competing tight transition state to the roaming products. The results of the $\operatorname{CSD}(\mathrm{T}) / \mathrm{CBS} / /$ $\operatorname{CCSD}(\mathrm{T}) /$ aug-cc-pVDZ calculations are summarized in Table 4 and Fig. 15. Reaction (R7) is nominally Woodward-Hoffman forbidden. All attempts to find a tight transition state for (R7) failed. The high pressure rate constants for dissociation to channels (R4), (R5), (R6) 
(a)

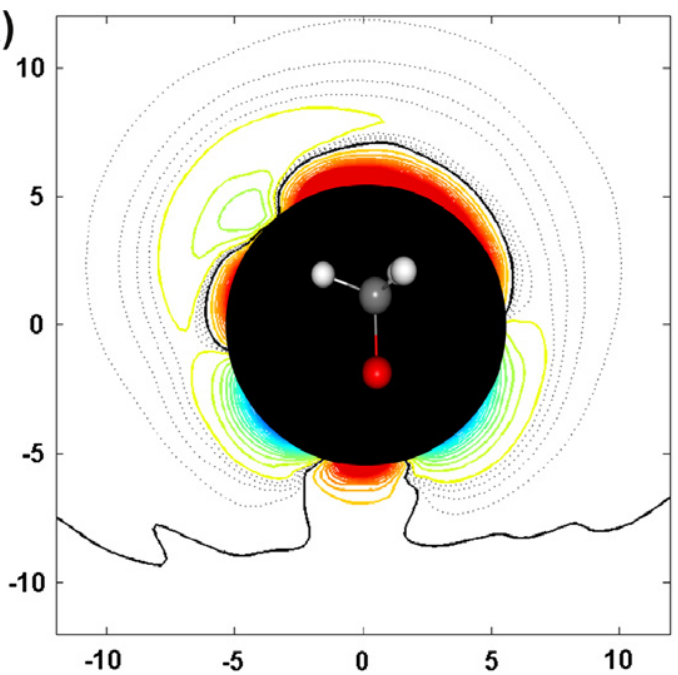

(b)

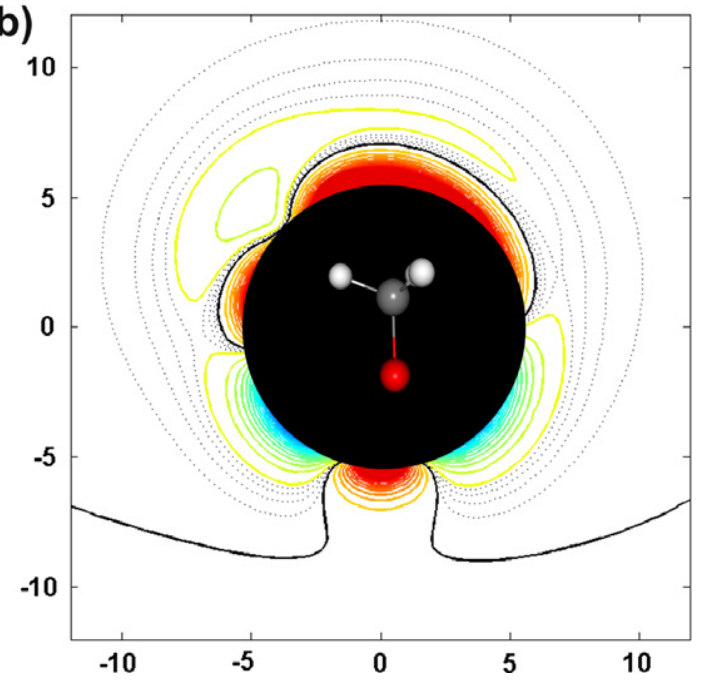

Fig. 10. Contour plots of the $\mathrm{CH}_{3} \mathrm{O}+\mathrm{CH}_{3}$ interaction potential. Plot (a) is of the automatically generated IMLS PES fit to the CASPT2/aug-cc-pVDZ data. Plot (b) is a two-dimensional spline fit directly to a $100 \times 100$ grid of ab initio data points. Contours are: color $(1 \mathrm{kcal} / \mathrm{mol}$ spacing), dashed $(-0.2,-0.4, \ldots,-0.8)$, solid $(0.0)$. Increasingly blue contours are attractive, while increasingly red are repulsive. (For interpretation of the references to color in this figure legend, the reader is referred to the web version of this article.)

were evaluated with transition state theory and compared with the calculated high pressure rate constant for the dissociation to $\mathrm{CH}_{3}+\mathrm{CH}_{3} \mathrm{O}(\mathrm{R} 1)$.

Reaction (R4) is predicted to be $12 \mathrm{kcal} / \mathrm{mol}$ higher than the $\mathrm{CH}_{3} \mathrm{O}+\mathrm{CH}_{3}$ asymptote, comparable to the difference found [17] in $\mathrm{CH}_{3} \mathrm{CHO}$ for the analogous channel to form $\mathrm{H}+\mathrm{CH}_{2} \mathrm{CHO}$. Presuming a typical reverse recombination rate constant of $4 \times 10^{-10} \mathrm{~cm}^{3}$ molecule $\mathrm{e}^{-1} \mathrm{~s}^{-1}$ for this channel implies that this channel contributes at most $1.7 \%$ or less to the total decomposition rate constant for temperatures of $2000 \mathrm{~K}$ or lower. Furthermore, reaction (R4) also results in the formation of one hydrogen atom for each DME molecule destroyed and so would have essentially no effect on the measured branching ratio.

Reaction (R5) results first in the formation of a long-range complex between ${ }^{1} \mathrm{CH}_{2}$ and $\mathrm{CH}_{3} \mathrm{OH}$. This complex lies $14 \mathrm{kcal} /$ mol below ${ }^{1} \mathrm{CH}_{2}+\mathrm{CH}_{3} \mathrm{OH}$ and $1 \mathrm{kcal} / \mathrm{mol}$ below the $\mathrm{CH}_{3} \mathrm{O}+\mathrm{CH}_{3}$ asymptote. However, the barrier to formation of this complex from DME is predicted to lie $1 \mathrm{kcal} / \mathrm{mol}$ above the $\mathrm{CH}_{3} \mathrm{O}+\mathrm{CH}_{3}$ asymptote. The possibility of an isomerization of DME to ethanol via the $\mathrm{CH}_{3} \mathrm{OH} \cdots{ }^{1} \mathrm{CH}_{2}$ complex was also considered. The transition

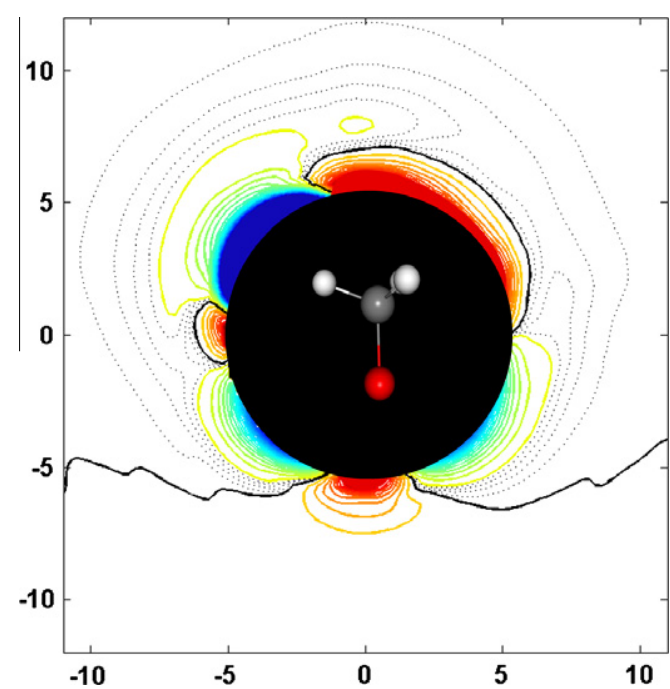

Fig. 11. Contour plot of the $\mathrm{CH}_{3} \mathrm{O}+\mathrm{CH}_{3}$ interaction potential from the IMLS fit including the $1 \mathrm{D}$ potential corrections (with the same contours as Fig. 10). (For interpretation of the references to color in this figure legend, the reader is referred to the web version of this article.)

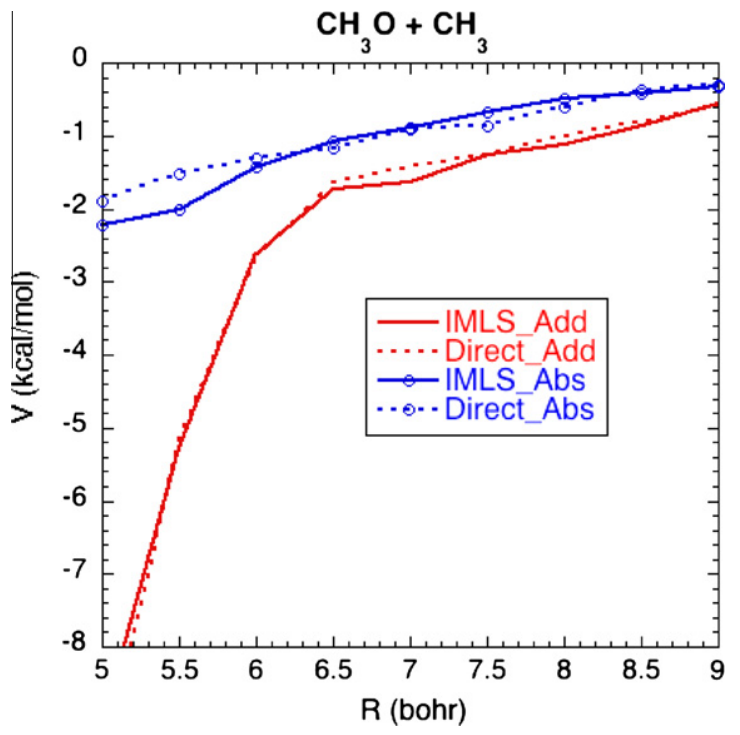

Fig. 12. Plots of IMLS fit and ab initio data along the addition (red lines) and abstraction (blue lines with open circles) reaction paths. The solid and dashed lines denote the IMLS fit and ab initio data, respectively. For the addition $\mathrm{R}$ denotes the $\mathrm{C}^{\prime} \mathrm{O}$ distance, while for the abstraction it denotes the $\mathrm{C}^{\prime} \mathrm{H}$ distance. (For interpretation of the references to color in this figure legend, the reader is referred to the web version of this article.)

state for this process is predicted to lie $11 \mathrm{kcal} / \mathrm{mol}$ above the $\mathrm{CH}_{3} \mathrm{O}+\mathrm{CH}_{3}$ asymptote (see Table 4 ). The high pressure rate constant for formation of the $\mathrm{CH}_{3} \mathrm{OH} \cdots{ }^{1} \mathrm{CH}_{2}$ complex is less than $0.5 \%$ of the total decomposition rate constant at $2000 \mathrm{~K}$. Thus, both (R5) and the isomerization process to ethanol will not contribute significantly for the range of temperature and pressure studied experimentally.

The transition state for reaction (R6) is only $1 \mathrm{kcal} / \mathrm{mol}$ above that for (R1). However, this 1, 1 elimination transition state is very tight with low entropy. As a result, the maximum contribution to the high pressure decomposition rate from this channel is predicted to be less than $0.4 \%$ for temperatures of $2000 \mathrm{~K}$ and lower.

The contributions from each of these channels will be greatly reduced away from the high pressure limit. For example, for 


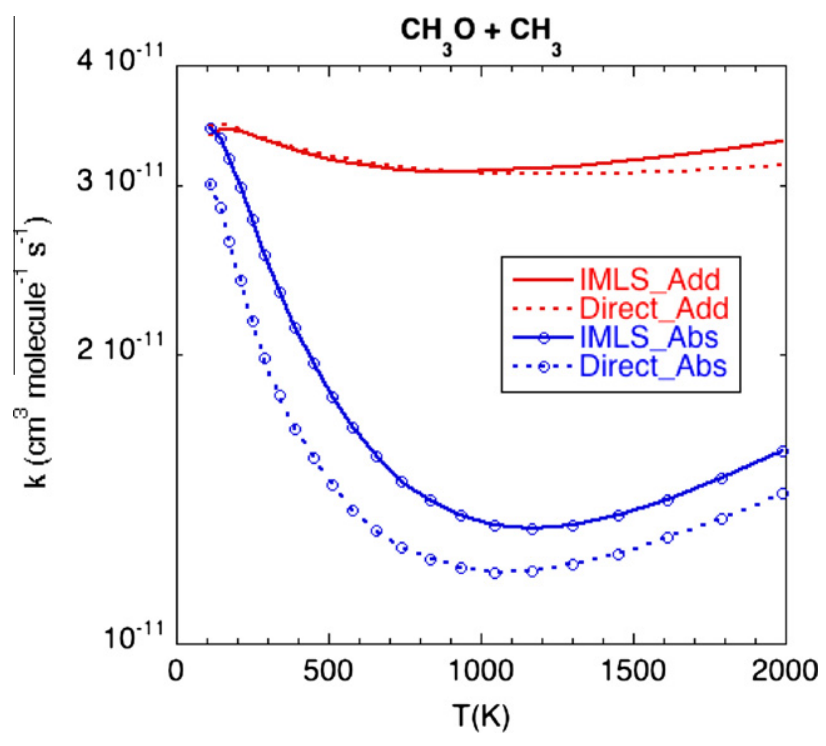

Fig. 13. Plot of the calculated high pressure rate coefficients for addition and abstraction employing either directly sampled ab initio data (dashed lines) or the IMLS potential (solid lines). Both calculations also include the "one-dimensional" corrections. The red lines are for the addition reaction while the blue lines are for the abstraction reaction. (For interpretation of the references to color in this figure legend, the reader is referred to the web version of this article.)
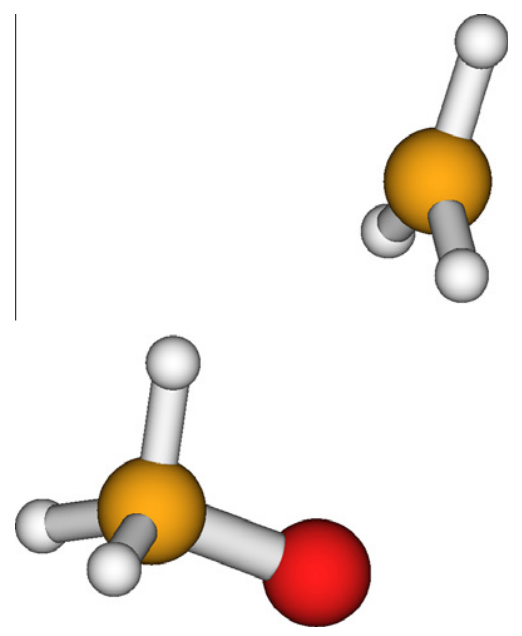

Fig. 14. Structure of the saddle point for the roaming-radical pathway.

$\mathrm{H}+\mathrm{CH}_{3} \mathrm{OCH}_{2}$ this maximum contribution is reduced to $0.01 \%$ at the experimental pressure of $\sim 1 \mathrm{~atm}$. In summary, it is clear that none of these channels will have a significant bearing on the observed branching ratios.

\subsubsection{Roaming dynamics}

The results of the RDT predictions of the roaming and radical fluxes on the corrected $\mathrm{CH}_{3} \mathrm{OCH}_{3}$ PES described in Section 3 are reported in Fig. 16. The energy $E$ in the figure is measured with respect to the dissociation threshold for $\mathrm{R} 1(E=0)$. The range of the energy $E$ and the transitional mode sum of states $N(E)$ are almost identical to the results of $\mathrm{CH}_{3} \mathrm{CHO}$ reported in Fig. 12 of Ref. [17]. (Those results are reproduced in Fig. 16.) Qualitatively the roaming $N(E)$ in $\mathrm{CH}_{3} \mathrm{OCH}_{3}$ is similar to that in $\mathrm{CH}_{3} \mathrm{CHO}$, but the dissociative $N(E)$ is systematically larger and growing increasingly larger with increasing energy relative to that in $\mathrm{CH}_{3} \mathrm{CHO}$. At a more quantitative level, for energies below the dissociation threshold, the roaming $N(E)$ for $\mathrm{CH}_{3} \mathrm{OCH}_{3}$ is systematically larger than that in $\mathrm{CH}_{3} \mathrm{CHO}$
Table 4

Calculated $\operatorname{CCSD}(\mathrm{T}) / \mathrm{CBS} / / \mathrm{CCSD}(\mathrm{T}) /$ aug-cc-pvdz energies relative to DME for the stationary points on the $\mathrm{C}_{2} \mathrm{H}_{6} \mathrm{O}$ potential surface.

\begin{tabular}{ll}
\hline Species & Energy $^{\mathrm{a}}(\mathrm{kcal} / \mathrm{mol})$ \\
\hline $\mathrm{CH}_{3}+\mathrm{CH}_{3} \mathrm{O}$ & $90.7(82.5)$ \\
$\mathrm{H}_{2} \mathrm{CO}+\mathrm{CH}_{4}$ & $4.1(-1.1)$ \\
$\mathrm{H}+\mathrm{CH}_{3} \mathrm{OCH}_{2}$ & $103.4(94.9)$ \\
$\mathrm{CH}_{3} \mathrm{OH}+{ }^{1} \mathrm{CH}_{2}$ & $103.5(96.3)$ \\
$\mathrm{CH}_{3} \mathrm{OCH}+\mathrm{H}_{2}$ & $80.0(70.7)$ \\
$\mathrm{CH}_{3} \mathrm{OH}-{ }^{1} \mathrm{CH}_{2}$ & $84.0(82.0)$ \\
$\mathrm{CH}_{3} \mathrm{OCH}$ & $\rightarrow \mathrm{CH}_{3} \mathrm{OH}-{ }^{1} \mathrm{CH}_{2}$ \\
$\mathrm{CH}_{3} \mathrm{OCH}$ & $88.1(83.8)$ \\
$\mathrm{CH}_{3} \mathrm{CH}_{2} \mathrm{OH} \rightarrow \mathrm{CH}_{3} \mathrm{OCH}+\mathrm{H}_{2} \mathrm{OH}-{ }^{1} \mathrm{CH}_{2}$ & $91.2(84.2)$ \\
\hline
\end{tabular}

a Numbers in parenthesis include zero point.

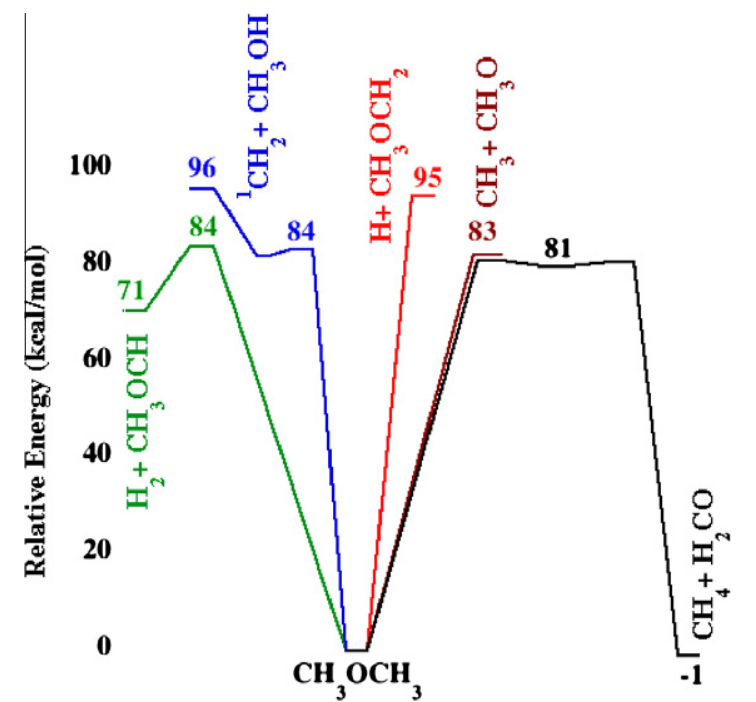

Fig. 15. Schematic of the energetics for the pathways for decomposition of DME.

as a consequence, as noted earlier, of the more negative roaming saddle point energy.

The corrections for geometry relaxation, zero-point energy changes in conserved modes, and basis set saturation are very significant, even more so than in $\mathrm{CH}_{3} \mathrm{CHO}$. For example, the calculations at an energy of $4 \mathrm{kcal}$ on the uncorrected PES show that the roaming $N(E)$ is typically lower by a factor of $\sim 20$ relative to the corrected PES while the dissociative $N(E)$ is typically higher by a factor of $\sim 1.5$. On $\mathrm{CH}_{3} \mathrm{CHO}$ at the same energy, roaming was a factor of five reduced on the uncorrected relative to the corrected PES. We have represented the corrections with only a few local calibration calculations (see Fig. 1) interpolated globally in a reasonable but not rigorous way. Sample calculations with a variety of alternative correction potentials employing different interpolation schemes yield small variations. In particular, the predicted $N(E)$ for the dissociation channel is essentially independent of the interpolation form while the predicted roaming $N(E)$ can vary by up to a factor of two. The largest variations occur in the roaming threshold region where the different forms resulted in substantially different roaming saddle point energies. Such low energy variations tend to have an insignificant effect on the predicted thermal kinetics because the reaction occurs at energies where the rate constant is comparable to the collision timescale, i.e., near the threshold and above for this reaction. Qualitatively, the present three cut representation appears to be reasonably converged but in future work we will provide a more complete examination of these corrections.

The larger transitional mode dissociative flux for $\mathrm{CH}_{3} \mathrm{OCH}_{3}$ than for $\mathrm{CH}_{3} \mathrm{CHO}$ is related to the fact that the approach of $\mathrm{CH}_{3}$ to the $\mathrm{O}$ 


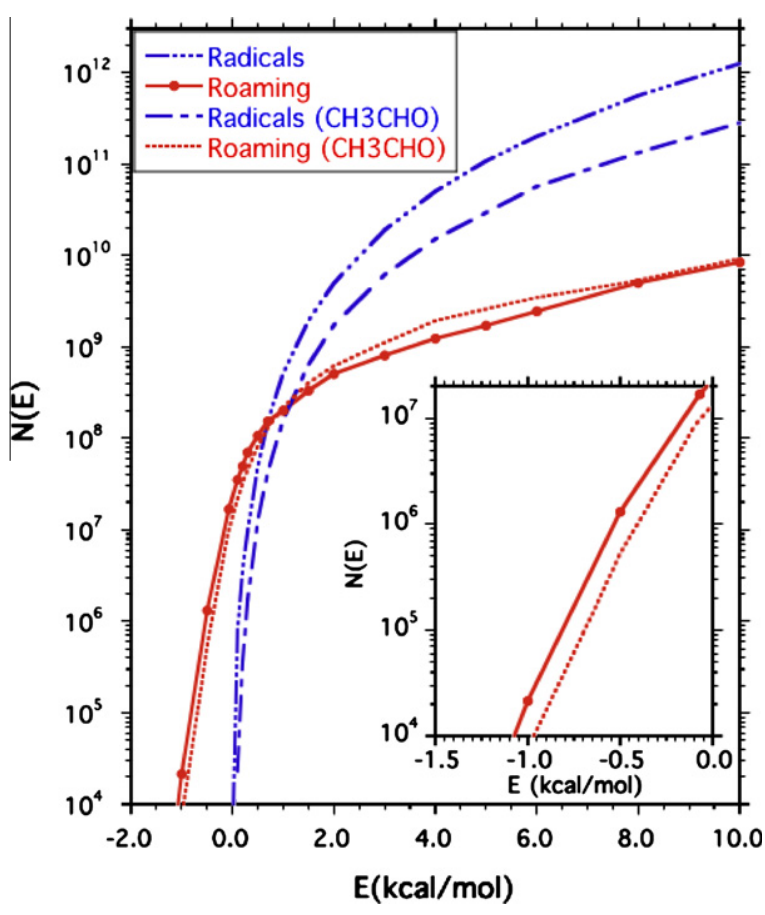

Fig. 16. Calculated sum of states $N(E)$ for the six transitional degrees of freedom versus energy $E$. Results for dissociation to radicals are indicated in blue while results for roaming are indicated in red. For acetaldehyde, the results are identical to Ref. [17] and are reproduced here for comparison. The insert is a blowup of the results for $E<0$. The dots indicate the specific energies at which flux calculations were carried out. (For interpretation of the references to color in this figure legend, the reader is referred to the web version of this article.)

end of $\mathrm{CH}_{3} \mathrm{O}$ is highly attractive for the full range of $\mathrm{HCOC}$ torsional angles. In contrast, the approach of $\mathrm{CH}_{3}$ to $\mathrm{HCO}$ corresponds to a strongly attractive formation of $\mathrm{CH}_{3} \mathrm{CHO}$ only for in-plane attack from one side of the $\mathrm{HCO}$ group. As a result the entropic reduction of the flux is greater for the $\mathrm{CH}_{3} \mathrm{CHO}$ dissociation and this reduction increases with increasing energy as the transition state moves to closer separations.

The larger roaming flux for $\mathrm{CH}_{3} \mathrm{OCH}_{3}$ than for $\mathrm{CH}_{3} \mathrm{CHO}$ for $E<0$ is also not surprising, given that the saddle point barrier for roaming in $\mathrm{CH}_{3} \mathrm{CHO}$ is $\sim-1.0 \mathrm{kcal} / \mathrm{mol}$, about $0.6 \mathrm{kcal} / \mathrm{mol}$ higher than in $\mathrm{CH}_{3} \mathrm{OCH}_{3}$. However, for $E>0$, the roaming flux is surprisingly similar between the two systems. To confirm the consistency of the IMLS based PES with the method previously applied to $\mathrm{CH}_{3} \mathrm{CHO}$, an analogous IMLS PES was calculated for $\mathrm{CH}_{3} \mathrm{CHO}$ and the RDT method was applied to produce roaming and dissociative $N(E)$ at selected energies. Although this will be the subject of a more comprehensive paper in the future, we note here that the resulting values of the dissociative and roaming $N(E)$ differ by less than $15 \%$ at $E=3$ and $10 \mathrm{kcal} / \mathrm{mol}$ from the published results [17] on a nonIMLS PES

\subsection{DME decomposition kinetics: comparison of theory and experiment}

The results for $k_{1}$ from Tables 2 and 3 and the theoretical predictions from the present work are compared in Figs. 17 and 18 to earlier decomposition studies [4-10] at high and low temperature, respectively. The data in Tables 2 and 3 are represented in both figures (and also Fig. 19) but for clarity, the different pressures are binned into groups. The pressures represented in each single density group in Table 2 vary by $<10 \%$ about the mean value of the bin. If the data from Tables 2 and 3 together are considered, the dispersion increases marginally to about $\pm 15 \%$ from the mean

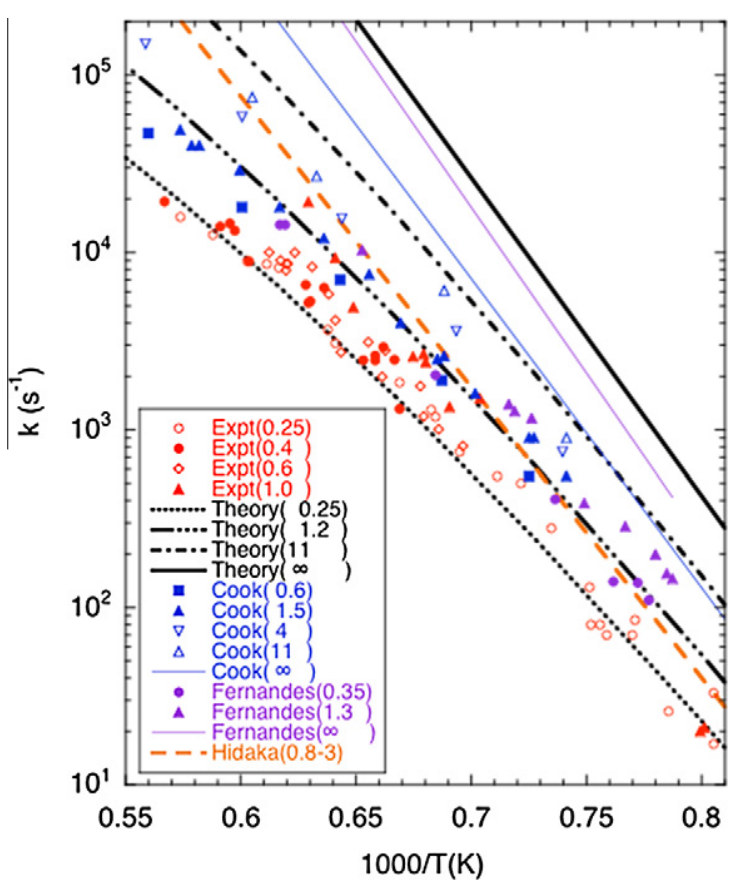

Fig. 17. First order rate constants for $\mathrm{CH}_{3} \mathrm{OCH}_{3} \rightarrow \mathrm{CH}_{3} \mathrm{O}+\mathrm{CH}_{3}$ at high temperature and for the pressures (bar) listed in parentheses. Red symbols - present data, blue symbols and line - Cook et al. [10], purple symbols and line- Fernandes et al. [9] orange dashed line - Hidaka et al. [8], black lines - present theory. (For interpretation of the references to color in this figure legend, the reader is referred to the web version of this article.)

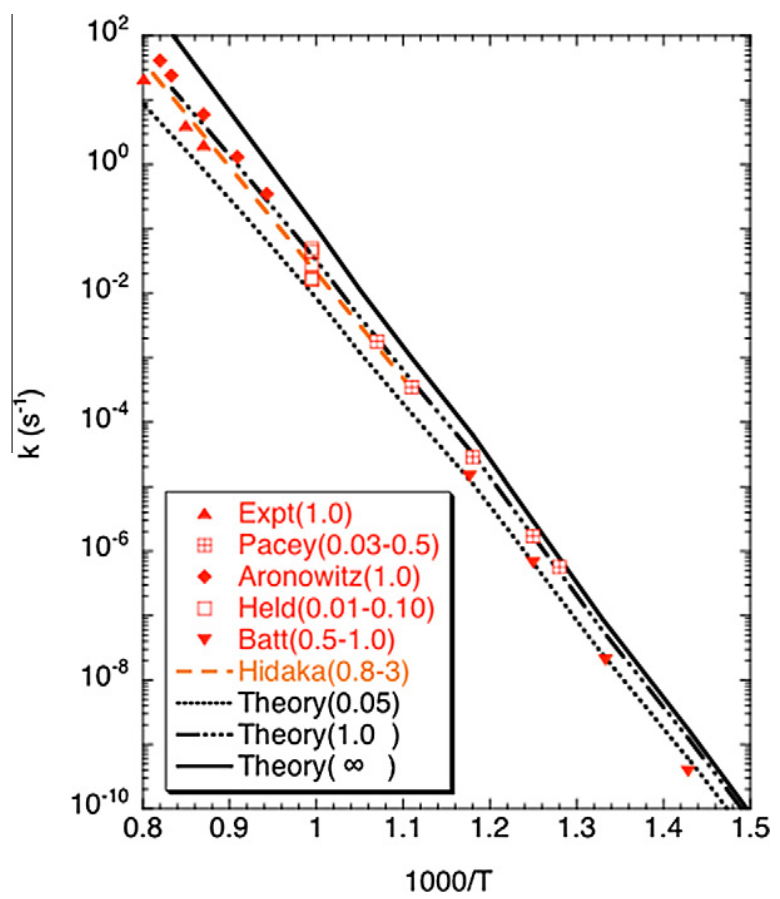

Fig. 18. First order rate constants for $\mathrm{CH}_{3} \mathrm{OCH}_{3} \rightarrow \mathrm{CH}_{3} \mathrm{O}+\mathrm{CH}_{3}$ at low temperature and for the pressures (bar) listed in parentheses. Open circles- present data, thatched square - Pacey [4], solid diamond - Aronowitz and Naegeli [5], open squares - Held et al. [6], downward solid triangle - Batt et al. [7], orange dashed line - Hidaka et al. [8]; black lines - present theory. (For interpretation of the references to color in this figure legend, the reader is referred to the web version of this article.)

value. In Fig. 17, the present measurements in the highest pressure bin (1.0 bar) are in reasonable agreement with the two recent high- 


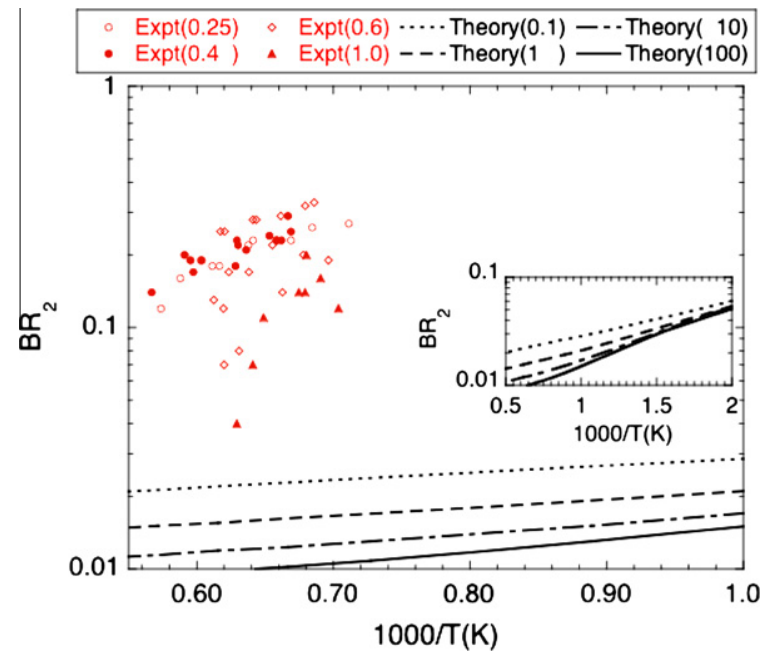

Fig. 19. Experimentally measured and theoretical predicted roaming branching ratio as a function of inverse temperature with pressure (bar) listed in parentheses. Insert plot is for theory alone over the extend temperature range of all DME kinetics measurements.

temperature studies by Fernandes et al. [9] and Cook et al. [10] at comparable pressures (1.3 and 1.5 bar, respectively). The observed fall-off however is more severe at the lowest-P of the present study in comparison to these two recent studies. At the lowest pressures ( 0.25 bars) the present data for $k_{1}$ are lower by a factor of 2 than the two recent measurements $[9,10]$ over similar pressure ranges. In the case of Fernandes et al. [9], the discrepancy might be attributed to the $T$-invariant choice for $k_{3}$ when modeling their $[\mathrm{H}]$ profiles. On the other hand, the $\mathrm{OH}$-absorption measurements of Cook et al. [10] are sensitive to a number of abstraction reactions, $\mathrm{DME}+\mathrm{OH}$ and $\mathrm{DME}+\mathrm{H}$, apart from $\mathrm{H}+\mathrm{O}_{2} \rightarrow \mathrm{O}+\mathrm{OH}$, and consequently required using a detailed model to extract $k_{1}$ and this might be a reason for the observed discrepancies with the present data. The representation of Hidaka et al., which ignores the dependence on pressure, is reasonably concordant with the present data.

The theoretical predictions for $k_{1}$, which employ a fitted $\left\langle\Delta E_{\text {down }}\right\rangle$, accurately reproduce the experimental data presented in this paper. They also provide a satisfactory representation of the low temperature data from [4-7], particularly when one considers the predicted deviations from the high pressure limit. Furthermore, they are reasonably representative of the data of Cook et al. [10] and Fernandes et al. [9], although, as noted above, there are deviations of about a factor of 2 toward lower pressures. Over the whole temperature range in Fig. 17, the present theoretical prediction for the high pressure limit is slightly larger than that derived by Fernandes et al. [9] and larger by a factor of 3-4 than that derived by Cook et al. [10]. The present theoretical predictions are well reproduced over the $500-2000 \mathrm{~K}$ temperature range and the 0.01-300 bar pressure range by the following modified Arrhenius parameters for the Troe falloff format:

$$
\begin{aligned}
& k_{1, \infty}(T)=2.33 \times 10^{19} T^{-0.661} \exp (-42345 / T) \mathrm{s}^{-1} \\
& k_{1,0}(T)=2.86 \times 10^{35} T^{-11.4} \exp (-46953 / T) \mathrm{cm}^{3} \text { molecule }^{-1} \mathrm{~s}^{-1} \\
& F_{\text {cent }}(T)=\exp (-T / 880)
\end{aligned}
$$

Figure 19 provides a comparison of the temperature and pressure dependence of the present theoretical predictions for the roaming branching, $\mathrm{BR}_{2}$, with the experimental measurements. The theoretical prediction of $\sim 0.02$ for the experimental conditions dramatically underestimates the experimentally observed value. As the insert in the figure shows, over the whole range of DME kinetics measurements down to $650 \mathrm{~K}$, the theory predicts an increasing $\mathrm{BR}_{2}$ with decreasing temperature and pressure, trends that as mentioned above are discernable in the experimental data. However, over the full temperature range, the calculated $\mathrm{BR}_{2}$ never exceeds $10 \%$, while the measurements are 10 times larger at the high temperatures of $1400-1750 \mathrm{~K}$. It is not clear why this should be the case. There are a number of aspects to the present calculation that could introduce errors, such as inaccuracies in the trajectory propagation, failures of the reduced dimensional framework, inaccuracies in the treatment of energy transfer, the neglect of dynamical effects arising from Jahn-Teller and spin-orbit interactions and, perhaps most notably, inaccuracies of the potential energy surface, especially those related to the "one-dimensional" corrections. Nevertheless, it is hard to envision how any of these inadequacies would yield an order of magnitude increase in the predicted branching ratio.

It is interesting to note that the present RDT-based estimate for $\mathrm{BR}_{2}$ is even lower than that predicted for the decomposition of $\mathrm{CH}_{3} \mathrm{CHO}$. The magnitude of roaming for the thermal dissociation arises from a convolution of the energy dependent roaming flux (cf. Fig. 16) with the steady state distribution for dissociation. The results in Fig. 16 indicate that, if the threshold region of roaming (i.e., $E<0$ ) dominates, $\mathrm{BR}_{2}$ for $\mathrm{CH}_{3} \mathrm{OCH}_{3}$ will be larger than that for $\mathrm{CH}_{3} \mathrm{CHO}$. If, instead, the region above the threshold for dissociation (i.e., $E>0$ ) dominates, $\mathrm{BR}_{2}$ for $\mathrm{CH}_{3} \mathrm{OCH}_{3}$ will be smaller than that for $\mathrm{CH}_{3} \mathrm{CHO}$. At $1500 \mathrm{~K}$, with only a $2 \mathrm{kcal} / \mathrm{mol}$ difference in thresholds for roaming as opposed to radical formation, the region above the threshold dominates and $\mathrm{BR}_{2}$ is larger for $\mathrm{CH}_{3} \mathrm{CHO}$. This discussion also indicates that the smallness of the roaming for DME arises from the very small ratio of the roaming to radical fluxes at high energy. What is not clear is why this ratio should be so much smaller for DME than for $\mathrm{CH}_{3} \mathrm{CHO}$.

\section{Conclusions}

The contribution of the roaming channel to the total thermal dissociation rate in dimethyl ether is measured to be $0.19 \pm 0.07$ for temperatures in the range from 1406 to $1764 \mathrm{~K}$ and pressures in the range $0.2-1.25 \mathrm{~atm}$. The combination of these measurements with the theoretical analysis provides definitive evidence for a contribution from a roaming radical mechanism in this thermal decomposition, although the theoretical analysis does suggest that this roaming should be an order of magnitude lower. In the studied range there is evidence that the branching ratio has trends with temperature and pressure that are in the same direction as those found in the theoretical analysis.

In contrast, the theoretical predictions for the thermal DME decomposition rate constant for formation of radical products $\mathrm{CH}_{3}+\mathrm{OCH}_{3}$ accurately reproduced the experimental measurements. Troe format expressions for the temperature and pressure dependence of this rate constant were obtained from the theoretical analysis. The rate coefficient for the $\mathrm{CH}_{3} \mathrm{OCH}_{3}+\mathrm{H}$ reaction was also measured in the present experimental work using more concentrated mixtures than those used in the yield experiments. An evaluation of the data from 273 to $1465 \mathrm{~K}$ yields the expression given in Eq. (E3).

This study is the first application of IMLS PES generation for use in an RDT study of roaming. This application illustrates the trade-offs with the IMLS approach. The production level generation of the PES took less than a week with little human intervention and involved $\sim 4000 \mathrm{ab}$ initio calculations generally done in groups of 20 in parallel. This is much faster than generating the PES for $\mathrm{CH}_{3} \mathrm{CHO}$ by non-IMLS means where extensive human intervention 
and 20 times the number of ab initio calculations were required. However, the resulting non-IMLS $\mathrm{CH}_{3} \mathrm{CHO}$ PES involves evaluating only a handful of expansions to obtain an energy on the PES, while the IMLS PES for $\mathrm{CH}_{3} \mathrm{OCH}_{3}$ involves evaluating one or two orders of magnitude more expansions to obtain an energy. As a result, RDT calculations on the IMLS PES for $\mathrm{CH}_{3} \mathrm{OCH}_{3}$ took from a day to a week while RDT calculations on the non-IMLS PES for $\mathrm{CH}_{3} \mathrm{CHO}$ typically took at most a few hours. In effect, the IMLS approach has greatly reduced human intervention time and shifted computer resource allocations from generation to application. Methods for speeding up IMLS PES evaluations (such as simpler distance metrics or nearest-neighbor lists in trajectory applications) are currently under investigation.

As part of an effort to uncover the origins of the difference in the roaming branching ratio between theory and experiment, we are carrying out further roaming studies on $\mathrm{CH}_{3} \mathrm{OCH}_{3}$ and also on $\mathrm{CH}_{3} \mathrm{CHO}$ and $\mathrm{CH}_{3} \mathrm{C}_{2} \mathrm{H}_{5}$. The global reliability of 1 -D correction terms, the impact of local improvements to the PES (e.g., the abstraction region for $\mathrm{CH}_{3}+\mathrm{OCH}_{3}$ ), and the limitations of rigid fragment approximations are being investigated.

\section{Acknowledgments}

This work at Argonne was supported by the US Department of Energy, Office of Basic Energy Sciences, Division of Chemical Sciences, Geosciences, and Biosciences, under Contract No. DEAC02-06CH11357. RD and AWJ are supported by the Division of Chemical Sciences, Geosciences, and Biosciences, the Office of Basic Energy Sciences, the US Department of Energy; Sandia is a multiprogram laboratory operated by Sandia Corporation, a Lockheed Martin Company, for the National Nuclear Security Administration under contract DE-AC04-94-AL85000.

\section{Appendix A. Supplementary material}

Supplementary data associated with this article can be found, in the online version, at doi:10.1016/j.combustflame.2010.12.017.

\section{References}

[1] http://www.aboutdme.org.

[2] A.L. Boehman, Fuel Process. Technol. 89 (2008) 1243.

[3] Z. Zhao, M. Chaos, A. Kazakov, F.L. Dryer, Int. J. Chem. Kinet. 40 (2008) 1-18.

[4] P.D. Pacey, Can. J. Chem. 53 (1975) 2742-2747.

[5] D. Aronowitz, D. Naegeli, Int. J. Chem. Kinet. 9 (1977) 471-479.

[6] A.M. Held, K.C. Manthorne, P.D. Pacey, H.P. Reinholdt, Can. J. Chem. 55 (1977) 4128-4134.

[7] L. Batt, G. Alvarado-Salinas, I.A.B. Reid, C. Robinson, D.B. Smith, Proc. Combust. Inst. 19 (1982) 81-87.

[8] Y. Hidaka, K. Sato, M. Yamane, Combust. Flame 123 (2000) 1-22.

[9] R.X. Fernandes, C. Fittschen, H. Hippler, React. Kinet. Catal. Lett. 96 (2009) 279289.

[10] R.D. Cook, D.F. Davidson, R.K. Hanson, J. Phys. Chem. A 113 (2009) 9974-9980.

[11] L.B. Harding, S.J. Klippenstein, J. Phys. Chem. Lett. 1 (2010) 3016-3020.

[12] D. Townsend, S.A. Lahankar, S.K. Lee, S.D. Chambreau, A.G. Suits, X. Zhang, J.L. Rheinecker, L.B. Harding J.M. Bowman, Science 306 (2004) 1158-1161.

[13] P.L. Houston, S.H. Kable, Proc. Natl. Acad. Sci. 103 (2006) 16079-16082.
[14] B.R. Heazlewood, M.J.T. Jordan, S.H. Kable, T.M. Selby, D.L. Osborn, B.C. Shepler, B.J. Braams, J.M. Bowman, Proc. Natl. Acad. Sci. 105 (2008) 12719-12724.

[15] B.S. Shepler, B.J. Braams, J.M. Bowman, J. Phys. Chem. A 112 (2008) 9344-9351

[16] R. Sivaramakrishnan, J.V. Michael, S.J. Klippenstein, J. Phys. Chem. A 114 (2010) 755-764.

[17] L.B. Harding, Y. Georgievskii, S.J. Klippenstein, J. Phys. Chem. A 114 (2010) 765-777.

[18] (a) R. Dawes, A.F. Wagner, D.L. Thompson, J. Phys. Chem. A 113 (2009) 47094721 ;

(b) R. Dawes, D.L. Thompson, A.F. Wagner, M. Minkoff, J. Chem. Phys. 128 (2008) 084107;

(c) R. Dawes, D.L. Thompson, Y. Guo, A.F. Wagner, M. Minkoff, J. Chem. Phys. 126 (2007) 184108;

(d) Y. Guo, I. Tokmakov, D.L. Thompson, A.F. Wagner, M. Minkoff, J. Chem. Phys. 127 (2007) 214106.

[19] J.V. Michael, A. Lifshitz, in: G. Ben-Dor, O. Igra, T. Elperin, A. Lifshitz (Eds.) Handbook of Shock Waves, vol. 3, Academic Press, New York, 2001, pp. 77105.

[20] S.S. Kumaran, J.J. Carroll, J.V. Michael, Proc. Combust. Inst. 27 (1998) 125-133.

[21] K. Takahashi, O. Yamamoto, T. Inomata, M. Kogoma, Int. J. Chem. Kinet. 39 (2007) 97-108.

[22] J.V. Michael, Prog. Energy Combust. Sci. 18 (1992) 327-347.

[23] J.V. Michael, in: J.R. Barker (Ed.) Advances in Chemical Kinetics and Dynamics, vol. I, JAI, Greenwich, 1992, pp. 47-112.

[24] J.V. Michael, J.W. Sutherland, Int. J. Chem. Kinet. 18 (1986) 409-436.

[25] J.V. Michael, J. Chem. Phys. 90 (1989) 189-198.

[26] J.V. Michael, J.R. Fisher, in: Y.W. Kim (Ed.), Seventeenth International Symposium on Shock Waves and Shock Tubes, AIP Conference Proceedings, vol. 208, American Institute of Physics, New York, 1990, p. 210.

[27] S.S. Kumaran, J.J. Carroll, J.V. Michael, Proc. Combust. Inst. 27 (1998) 125-133.

[28] K.P. Lim, J.V. Michael, Proc. Combust. Inst. 25 (1994) 713-719 (and references therein).

[29] S.S. Kumaran, M.-C. Su, K.P. Lim, J.V. Michael, Proc. Combust. Inst. 26 (1996) $605-611$.

[30] R.G. Maki, J.V. Michael, J.W. Sutherland, J. Phys. Chem. 89 (1985) 4815-4821

[31] H.-J. Werner, Mol. Phys. 89 (1996) 645-661.

[32] P. Celani, H.-J. Werner, J. Chem. Phys. 112 (2000) 5546-5557.

[33] H.-J. Werner, P.J. Knowles, R. Lindh, F.R. Manby, M. Schütz, P. Celani, T. Korona, A. Mitrushenkov, G. Rauhut, T.B. Adler, R.D. Amos, A. Bernhardsson, A. Berning, D.L. Cooper, M.J.O. Deegan, A.J. Dobbyn, F. Eckert, E. Goll, C. Hampel, G. Hetzer, G. Knizia, C. Köppl, Y. Liu, A. W. Lloyd, R.A. Mata, A.J. May, S.J. McNicholas, W. Meyer, M.E. Mura, A. Nicklaß, P. Palmieri, K. Pflüger, R. Pitzer, M. Reiher, U. Schumann, H. Stoll, A. J. Stone, R. Tarroni, T. Thorsteinsson, M. Wang, A. Wolf, MOLPRO, Version 2009.1, a package of ab initio programs. <www.molpro.net>.

[34] R. Dawes, X.-G. Wang, A.W. Jasper, T. Carrington Jr., J. Chem. Phys. 133 (2010) 134304.

[35] (a) I.M. Sobol, USSR Comput. Maths. Math. Phys. 16 (1976) 236-242. in English;

(b) W.H. Press, S.A. Teukolsky, W.T. Vetterling, B.P. Flannery, Numerical Recipes in Fortran 77: The Art of Scientific Computing, second ed., Cambridge University Press, Cambridge, UK, 1992.

[36] R.N. Zare, Angular Momentum, Wiley, New York, 1988.

[37] J.A. Miller, S.J. Klippenstein, J. Phys. Chem. A 110 (2006) 10528-10544.

[38] A.W. Jasper, J.A. Miller, J. Phys. Chem. A 113 (2009) 5612-5619.

[39] A.E. Lutz, R.J. Kee, J.A. Miller, SAND87-8248 Revised, Sandia National Laboratory, November 1997.

[40] R.S. Tranter, R.W. Walker, Phys. Chem. Chem. Phys. 3 (2001) 4722-4732.

[41] C. Faubel, K. Hoyermann, E. Stroger, H. Gg. Wagner, Ber. Bunsen - Ges. Phys. Chem. 83 (1979) 532.

[42] J.H. Lee, R.C. Machen, D.F. Nava, L.J. Stief, J. Chem. Phys. 74 (1981) 2839-2844.

[43] J.F. Meagher, P. Kim, J.H. Lee, R.B. Timmons, J. Phys. Chem. 78 (1974) 26502657.

[44] F. Slemr, P. Warneck, Int. J. Chem. Kinet. 9 (1977) 267-282.

[45] J.Y. Wu, J. Y Liu, Z.S. Li, X.R. Huang, C.C. Sun, J. Comput. Chem. 24 (2003) 593600.

[46] Q.S. Li, Y. Zhang, S.W. Zhang, J. Phys. Chem. A 108 (2004) 2014-2019.

[47] L.N. Krasnoperov, E.N. Chesnokov, H. Stark, A.R. Ravishankara, J. Phys. Chem. A 108 (2004) 11526-11536.

[48] N.K. Srinivasan, M.-C. Su, J.W. Sutherland, J.V. Michael, J. Phys. Chem. A 109 (2005) 7902-7914. 